\title{
Agonist-Dependent and -Independent к Opioid Receptor Phosphorylation: Distinct Phosphorylation Patterns and Different Cellular Outcomes $\$$
}

\author{
Yi-Ting Chiu, Chongguang Chen, Daohai Yu, Stefan Schulz, and Lee-Yuan Liu-Chen
}

Center for Substance Abuse Research and Department of Pharmacology (Y.-T.C., C.C., L.-Y.L.-C.) and Department of Clinical Sciences (D.Y.), Lewis Katz School of Medicine, Temple University, Philadelphia, Pennsylvania; and Institute of Pharmacology and Toxicology, Jena University Hospital, Friedrich-Schiller-University, Jena, Germany (S.S.)

Received February 9, 2017; accepted August 10, 2017

\section{ABSTRACT}

We reported previously that the selective agonist $U 50,488 \mathrm{H}$ promoted phosphorylation of the mouse $\kappa$ opioid receptor (KOPR) at residues S356, T357, T363, and S369. Here, we found that agonist (U50,488H)-dependent KOPR phosphorylation at all the residues was mediated by $\mathrm{Gi} / \mathrm{o}_{\alpha}$ proteins and multiple protein kinases [GRK2, GRK3, GRK5, GRK6 and protein kinase C (PKC)]. In addition, PKC activation by phorbol ester induced agonistindependent KOPR phosphorylation. Compared with $\mathrm{U} 50,488 \mathrm{H}$, PKC activation promoted much higher S356/T357 phosphorylation, much lower T363 phosphorylation, and similar levels of S369 phosphorylation. After U50,488H treatment, GRKs, but not
PKC, were involved in agonist-induced KOPR internalization. In contrast, PKC activation caused a lower level of agonistindependent KOPR internalization, compared with $U 50,488 \mathrm{H}$. $\mathrm{U} 50,488 \mathrm{H}$-induced activation of extracellular signal-regulated kinase 1/2 (ERK1/2) was G protein-, but not $\beta$-arrestin-, dependent. After $\mathrm{U} 50,488 \mathrm{H}$ treatment, GRK-mediated, but not PKC-mediated, KOPR phosphorylation followed by $\beta$-arrestin recruitment desensitized $U 50,488 \mathrm{H}$-induced ERK1/2 response. Therefore, agonist-dependent (GRK- and PKC-mediated) and agonistindependent (PKC-promoted) KOPR phosphorylations show distinct phosphorylation patterns, leading to diverse cellular outcomes.

\section{Introduction}

The $\kappa$ opioid receptor (KOPR) is one of the three opioid receptors and belongs to the rhodopsin subfamily of $\mathrm{G}$ proteincoupled receptors (GPCRs). Activation of the KOPR produces many effects, including analgesia, antipruritic effects, water diuresis, hypothermia, sedation, and dysphoria (Simonin et al., 1998; Ansonoff et al., 2006; Lemos and Chavkin, 2011; Cowan et al., 2015). At the cellular level, activation of KOPR stimulates Gi/o protein-mediated signaling and KOPR phosphorylation. Phosphorylated receptor recruits $\beta$-arrestin, leading to desensitization, internalization, and $\beta$-arrestin-dependent signaling (for review, see Liu-Chen, 2004; Al-Hasani and Bruchas, 2011; Law, 2011). Gi/o protein-dependent responses include the inhibition of adenylyl cyclases and $\mathrm{Ca}^{2+}$ inward current, and activation of $\mathrm{K}^{+}$channels and ERK1/2 (early phase) (Al-Hasani and Bruchas, 2011; Law, 2011). $\beta$-Arrestin-dependent

This research was supported by the National Institutes of Health [DA036802, AT006899, and DA013429]. No potential conflicts of interest relevant to this article are reported.

An earlier version of this paper appears in bioR Xiv under the doi https:// doi.org/10.1101/137570.

https://doi.org/10.1124/mol.117.108555.

S This article has supplemental material available at molpharm. aspetjournals.org. signaling includes phosphorylation of ERK1/2 (late phase) and p38 mitogen-activated protein kinase (Al-Hasani and Bruchas, 2011; Law, 2011).

Previous studies using different strategies have shown that agonists cause KOPR phosphorylation. We have demonstrated that U50,488H induces phosphorylation of the human KOPR expressed in Chinese hamster ovary cells using metabolic labeling with ${ }^{32} \mathrm{P}$-orthophosphate (Li et al., 2002). Chavkin and colleagues (McLaughlin et al., 2003) reported that U50,488H induced rat KOPR (rKOPR) phosphorylation at S369 in human embryonic kidney 293 cells by immunoblotting. Recently, by liquid chromatographytandem mass spectrometry analysis, we determined the phosphorylation sites of the mouse KOPR (mKOPR) after U50,488H treatment to be S356, T357, T363, and S369 in the C-terminal domain (Chen et al., 2016). Antibodies were generated against three phosphopeptides containing pS356/pT357, pT363, or pS369, respectively. Affinitypurified antibodies were extensively characterized and found to be highly specific in immunoblotting for the mKOPR phosphorylated at S356/T357, T363, or S369 (Chen et al., 2016). U50,488H markedly enhanced the staining intensity of the KOPR by immunoblotting with these three phosphospecific antibodies, and the U50,488H effect was blocked by

ABBREVIATIONS: CHL, chelerythrine chloride; DDM, dodecyl- $\beta$-D-maltoside; ERK1/2, extracellular signal-regulated kinase 1/2; GPCR, G proteincoupled receptor; GRK, G protein-coupled receptor kinase; KOPR, $\kappa$ opioid receptor; MOPR, $\mu$ opioid receptor; N2A cells, neuro2A mouse neuroblastoma cells; Ni-NTA, nickel-nitrilotriacetate; NTF, no transfection; PBS, phosphate-buffered saline; PKC, protein kinase C; PMA, phorbol12-myristate-13-acetate; PTX, pertussis toxin; RT, reverse-transcription. 
the selective KOPR antagonist norbinaltorphimine, indicating that U50,488H-induced KOPR phosphorylation at these sites is KOPR-mediated (Chen et al., 2016).

However, the regulatory mechanisms of site-specific KOPR phosphorylation are not clear yet. In this study, we focused on agonist-dependent and agonist-independent KOPR phosphorylation. Which protein kinases were involved in site-specific KOPR phosphorylation and how protein kinase-mediated KOPR phosphorylation regulated functional outputs were examined.

\section{Materials and Methods}

\section{Materials}

Mouse neuro2A neuroblastoma (N2A) cells were purchased from the A.T.C.C. (Manassas, VA). U50,488H were provided by the National Institute on Drug Abuse (Bethesda, MD). Horseradish peroxidaseconjugated goat anti-rabbit or anti-mouse IgG antibodies were purchased from Jackson ImmunoResearch (West Grove, PA). Minimal essential medium, blasticidin, and Lipofectamine 2000 were purchased from Invitrogen/Thermo Fisher Scientific (Waltham, MA). Fetal bovine serum was purchased from Atlanta Biochemicals (Flowery Branch, GA). Protease inhibitor tablets and enhanced chemiluminescence reagent SuperSignal West Pico were purchased from Pierce/Thermo Fisher Scientific. Nickel-nitrilotriacetate (Ni-NTA) agarose was purchased from Qiagen (Hilden, Germany). Dodecyl- $\beta$-D-maltoside (DDM), Go6976, and polyvinylidene fluoride membranes were purchased from EMD Millipore (Billerica, MA). Chelerythrine chloride (CHL) was from Enzo Life Sciences (Farmingdale, NY). $\left[{ }^{3} \mathrm{H}\right]$ diprenorphine (specific activity, $37 \mathrm{Ci} / \mathrm{mmol}$ ) was purchased from PerkinElmer (Waltham, MA). Dynorphin A(1-17) was from Multiple Peptide Systems (San Diego, CA). Antibodies against total ERK1/2 (cat. no. 4696) and phosphorylated ERK1/2 (cat. no. 4370) were from Cell Signaling Technology (Danvers, MA). Secondary antibodies IRDye 800CW goat anti-rabbit IgG and IRDye680 goat anti-mouse IgG were from LI-COR Biosciences (Lincoln, NE). Takeda compound 101 (Compound 101; 3-[[[4-methyl-5(4-pyridyl)-4H-1,2,4-triazole-3-yl] methyl] amino]-N-[2-(trifluoromethyl) benzyl] benzamidehydrochloride) (Lowe et al., 2015) was from Hello Bio Inc. (Princeton, NJ). Antibodies against $\beta$-arrestin 1 and $\beta$-arrestin 2 were gifts from Dr. Jeffrey Benovic of Thomas Jefferson University (Philadelphia, PA). GRK5 cDNA in pcDNA3 was given by Dr. Walter Koch of Lewis Katz School of Medicine at Temple University (Philadelphia, PA).

The rabbit antibodies against mKOPR (PA847) and phosphospecific KOPR were custom generated by Covance (Conshohocken, PA) and purified in our laboratory (Chen et al., 2016). The antigens used were mKOPR (352-360) with pS356/pT357, mKOPR(357-367) with pT363, and mKOPR(365-373) with pS369, respectively.

Small interfering RNAs (siRNAs) targeting GRK2 (sc-35513), GRK3 (sc-35515), $\beta$-arrestin 1 (sc-29742), $\beta$-arrestin 2 (sc-29743), protein kinase C (PKC) $\alpha$ (sc-36244), and PKC $\varepsilon$ (sc-36250) and antibodies against GRK2 (sc-562) and GRK3 (sc-563) were purchased from Santa Cruz Biotechnology (Santa Cruz, CA). Polymerase chain reaction (PCR) primers for $\mathrm{PKC}$ isoforms $(\mathrm{PKC} \alpha, \operatorname{PKC} \beta, \operatorname{PKC} \gamma, \operatorname{PKC} \zeta, \operatorname{PKC} \iota / \lambda, \operatorname{PKC} \delta$, $\mathrm{PKC} \varepsilon, \operatorname{PKC} \theta$, and $\mathrm{PKC} \eta$ ) were also purchased from Santa Cruz Biotechnology. GRK4/5/6 antibody (cat. no. 05-466) was purchased from EMD Millipore. siRNAs against GRK5 and GRK6 and TRIzol Reagent were bought from Ambion by Life Technologies (Carlsbad, CA). The sense sequences of all the siRNAs used are listed in Supplemental Table 1. GF109203X, penicillin/streptomycin, pyruvic acid, $\mathrm{NaHCO}_{3}$, phorbol-12-myristate-13-acetate (PMA), tetrasodium pyrophosphate, glycerophosphate disodium, $\mathrm{NaF}$, orthovanadate $\left(\mathrm{Na}_{3} \mathrm{VO}_{4}\right)$, and all other chemicals were purchased from Sigma-Aldrich (St. Louis, MO).

\section{Cell Culture}

The mKOPR tagged with FLAG at the $\mathrm{N}$ terminus and $6 \times$ His-tag at the $\mathrm{C}$ terminus $(\mathrm{FmK} 6 \mathrm{H})$ was cloned into the vector pcDNA6. FmK6H was stably transfected into N2A cells, and stable clonal N2A-FmK6H cells were selected (Chen et al., 2016). Cells were grown in $10 \%$ fetal bovine serum, $2.2 \mathrm{~g} / \mathrm{NaHCO}_{3}, 110 \mathrm{mg} / \mathrm{l}$ pyruvic acid, $1 \mu \mathrm{g} / \mathrm{ml}$ blasticidin, minimal essential medium, and $100 \mathrm{U} / \mathrm{ml}$ penicillin/streptomycin in a humidified atmosphere with $5 \% \mathrm{CO}_{2}, 95 \%$ air at $37^{\circ} \mathrm{C}$.

\section{Drug Treatment}

Effects of U50,488H on KOPR Phosphorylation: Time Course and Dose-Response Relationship. Cells at $80 \%$ confluency were incubated in serum-free medium for at least 1 hour. For time-course experiments, cells were treated with vehicle or $0.1 \mu \mathrm{M}$ $\mathrm{U} 50,488 \mathrm{H}$ for different time intervals $(0,0.5,1,2,5$, and 10 minutes $)$ at $37^{\circ} \mathrm{C}$. For concentration-response relationship, cells were treated with vehicle or different concentrations of U50,488H $(0.01,0.1,0.3,1,3$, and $10 \mu \mathrm{M}$ ) for 2 minutes at $37^{\circ} \mathrm{C}$.

Roles of GRKs in U50,488H-Promoted KOPR Phosphorylation. For knockdown of GRK isoforms, $5 \times 10^{5}$ cells/well in six-well plates were left untransfected or transfected with control siRNA (siCtrl) or siRNA targeting GRK2, GRK3, GRK2 plus GRK3 (GRKs2+3), or GRK6 (75 pmol siRNA) using Lipofectamine 2000. Because GRK5 was not detected in N2A cells, the effects of both overexpression and overexpression/knockdown of GRK5 were examined. Cells were cotransfected with pcDNA3/siCtrl, GRK5 cDNA/siCtrl, pcDNA3/GRK5 siRNA, and GRK5 cDNA/GRK5 siRNA ( $1 \mu \mathrm{g}$ cDNA/100 pmol siRNA) using Lipofectamine 2000. Two days after transfection, cells were treated with vehicle or $3 \mu \mathrm{M} \mathrm{U} 50,488 \mathrm{H}$ for 2 minutes at $37^{\circ} \mathrm{C}$. Some cells were pretreated with compound $101(3 \mu \mathrm{M})$ (the concentration was based on the findings of the study by Lowe et al., 2015) for 30 minutes and then incubated with vehicle or $3 \mu \mathrm{M}$ U50,488H for 2 minutes.

Effects of PKC Activation on KOPR Phosphorylation. Cells $\left(\sim 10^{7}\right)$ were incubated in serum-free medium for at least 1 hour and then treated with different concentrations $(0.001,0.01,0.1,1$, and $10 \mu \mathrm{M})$ of PMA, a PKC activator, for 30 minutes or treated with $0.1 \mu \mathrm{M}$ PMA for different time points $(0,1,5,10$, and 30 minutes $)$ at $37^{\circ} \mathrm{C}$. For comparison, $3 \mu \mathrm{M}$ U50,488H was used for the same time intervals.

Effects of PKC Inhibition on U50,488H-Induced KOPR Phosphorylation. Cells $\left(\sim 10^{7}\right)$ were incubated with serum-free medium for 1 hour followed by incubation with vehicle or a PKC inhibitor (4 $\mu \mathrm{M}$ GF109203X, $1 \mu \mathrm{M}$ CHL, or $100 \mathrm{nM}$ Go6976) for 30 minutes and then were treated with vehicle or $3 \mu \mathrm{M} \mathrm{U} 50,488 \mathrm{H}$ for 2 minutes at $37^{\circ} \mathrm{C}$. Concentrations of the inhibitors used were based on previous publications (Herbert et al., 1990; Martiny-Baron et al., 1993; Jacobson et al., 1995); the $\mathrm{IC}_{50}$ values of these inhibitors for PKC isoforms were detailed in the Supplemental Material. Some cells were transfected with siCtrl or siRNA targeting PKC $\alpha$ or PKC $\varepsilon$ (75 pmol siRNA) using Lipofectamine 2000, and then 2 days later cells were treated with $3 \mu \mathrm{M}$ U50,488H for 2 minutes.

\section{Receptor Purification and Western Blot}

Receptor purification and subsequent immunoblotting were performed according to a simplified version of our published procedures (Chen et al., 2016). Briefly, after treatment, cells were lysed with lysis buffer [1\% DDM in $20 \mathrm{mM}$ Tris-HCl, pH 7.4, containing phosphatase inhibitors (20 mM tetrasodium pyrophosphate, $20 \mathrm{mM}$ glycerophosphate disodium, $20 \mathrm{mM} \mathrm{NaF}$, and $2 \mathrm{mM} \mathrm{Na}_{3} \mathrm{VO}_{4}$ ) and protease inhibitors] and centrifuged. The supernatant was incubated with Ni-NTA agarose for 1 hour and then washed with wash buffer $(0.1 \%$ DDM, $20 \mathrm{mM}$ imidazole, and $0.5 \mathrm{~N} \mathrm{NaCl}$ in $20 \mathrm{mM}$ Tris-HCl, $\mathrm{pH} 7.4$, containing phosphatase inhibitors at a 1:10 concentration). Samples were eluted with elution buffer ( $0.3 \mathrm{M}$ imidazole, $66 \mathrm{mM}$ Tris-free base, $0.3 \mathrm{M} \mathrm{NaCl}$, and $0.05 \% \mathrm{DDM}$ ), mixed with $5 \times$ sample loading buffer (10\% SDS, $0.25 \mathrm{M}$ Tris, pH 7.4, 50\% glycerol, and 0.01\% Bromophenol Blue, $25 \mu \mathrm{l}$ ), resolved with $8 \%$ SDS-PAGE and transferred onto polyvinylidene fluoride membranes. Membranes were incubated with phospho-specific KOPR antibodies ( $1 \mu \mathrm{g} / \mathrm{ml}$, pS356/pT357, pT363, and pS369) overnight followed by horseradish peroxidase-conjugated goat anti-rabbit IgG antibodies and then reacted with enhanced 
chemiluminescence reagents. Images were captured with LAS 1000 plus Image Analyzer (Fuji Photo Film Co. Ltd., Tokyo, Japan). Membranes were stripped and re-blotted for total mouse KOPR (antiPA847, 1:10,000). Intensities of phospho-KOPR were normalized against that of total KOPR in the same lane. Unless indicated otherwise, a U50,488H response (usually the maximal response) was designated as $100 \%$ and others were normalized against it.

\section{Reverse-Transcription PCR}

Cells $\left(\sim 10^{7}\right)$ were solubilized with $1 \mathrm{ml}$ TRIzol reagent followed by RNA extraction and precipitation for reverse-transcription (RT)-PCR. The following $\mathrm{PKC}$ isoforms were examined for their presence in $\mathrm{N} 2 \mathrm{~A}$ cells: conventional PKCs (PKC $\alpha, \operatorname{PKC} \beta$, and $\mathrm{PKC} \gamma)$, atypical PKCs $(\mathrm{PKC} \zeta$ and $\mathrm{PKC} \iota / \lambda)$, and novel $\mathrm{PKCs}(\mathrm{PKC} \delta, \mathrm{PKC} \varepsilon, \mathrm{PKC} \theta$, and $\mathrm{PKC} \eta$ ). RT-PCR was performed according to the semiquantitative nested RT-PCR protocol of the manufacturer (Santa Cruz Biotechnology). No-primer reaction was used as control. The PCR cycle was as follows: initial denaturing at $95^{\circ} \mathrm{C}$ for 30 seconds followed by 35 cycles $\left(95^{\circ} \mathrm{C}\right.$, 45 seconds; $55^{\circ} \mathrm{C}, 45$ seconds; $72^{\circ} \mathrm{C}, 1$ minute) and then the final elongation at $72^{\circ} \mathrm{C}$ for 10 minutes. PCR products were resolved with $1 \%$ agarose gel electrophoresis, and the image was captured with the LAS 1000 plus Image Analyzer (Fuji Photo Film Co. Ltd.).

\section{KOPR Internalization}

Cells were transfected with siCtrl or siRNAs targeting GRKs $2+3$ or GRK6. Two days later, cells were treated with vehicle or $3 \mu \mathrm{M}$ $\mathrm{U} 50,488 \mathrm{H}$ for 30 minutes. Some cells were treated with $0.1 \mu \mathrm{M}$ PMA for 30 minutes. Some other cells were incubated with a PKC inhibitor (4 $\mu \mathrm{M}$ GF109203X or $1 \mu \mathrm{M}$ CHL) for 30 minutes followed by $3 \mu \mathrm{M}$ U50,488H for 30 minutes. Cells were quickly suspended in phosphatebuffered saline (PBS) containing $1 \mathrm{mM}$ EDTA and then washed three times for 10 minutes with $0.1 \%$ bovine serum albumin in $\mathrm{PBS}$ at $4^{\circ} \mathrm{C}$ to remove PMA or U50,488H. KOPR internalization was determined by radioligand binding to KOPR in intact cells as described previously (Li et al., 1999). Receptor binding was carried out using $1 \mathrm{nM}$ $\left[{ }^{3} \mathrm{H}\right]$ diprenorphine. Specific binding to total receptors was defined in the presence of naloxone $(10 \mu \mathrm{M})$, whereas specific binding to cell surface receptors was determined in the presence of dynorphin A-(1-17) $(1 \mu \mathrm{M})$. Thus, the intracellular receptor pool can be calculated by subtracting cell surface receptor binding from total receptor binding. The internalized receptors were calculated as (intracellular receptor pool of U50,488H-treated group - intracellular receptor pool of control group)/intracellular receptor pool of control group.

\section{ERK1/2 Activation by U50,488H}

For time-course study, cells were treated with $3 \mu \mathrm{M} \mathrm{U} 50,488 \mathrm{H}$ at $37^{\circ} \mathrm{C}$ for different durations $(0,1,2,5,10,20$, and 30 minutes and 1,2 , 3 , and 4 hours). For involvement of $\mathrm{G}$ proteins, cells were treated with or without pertussis toxin (PTX) $\left(200 \mathrm{ng} / \mathrm{ml}\right.$, for 2 hours, at $\left.37^{\circ} \mathrm{C}\right)$ and subsequently with $3 \mu \mathrm{M}$ U50,488H or vehicle for 5 minutes or 1 hour. For the roles of GRKs and $\beta$-arrestins, cells were transfected with siRNA control or siRNA against GRKs $2+3$, GRK6, $\beta$-arrestin 1 , or $\beta$-arrestin 2 for 2 days as described above and then treated with $3 \mu \mathrm{M}$ $\mathrm{U} 50,488 \mathrm{H}$ for 5 minutes or 1 hour at $37^{\circ} \mathrm{C}$.

All treated cells were lysed with $2 \times$ Laemmli sample buffer $(4 \%$ SDS, $100 \mathrm{mM}$ dithiothreitol, $10 \%$ glycerol, $62.5 \mathrm{mM}$ Tris, and $0.01 \%$ Bromophenol Blue, pH 6.8). Cell lysate was subjected to $8 \%$ SDSPAGE, and resolved protein bands were then transferred onto nitrocellulose membranes. Membranes were incubated with primary antibodies against $\beta$-arrestin 1 (1:5000), $\beta$-arrestin 2 (1:6000), GRK2 (1:1000), GRK3 (1:1000), GRK4/5/6 (1:2000), or phosphorylated ERK1/2 (1:3000) and total ERK1/2 (1:3000) overnight at $4^{\circ} \mathrm{C}$ followed by goat anti-mouse IgG conjugated with infrared dye 680 or goat anti-rabbit IgG conjugated with infrared dye $800 \mathrm{CW}(1: 10,000$; LI-COR Biosciences). Images were captured with the Odyssey Infrared Imaging System (LI-COR Biosciences).

\section{Data Analysis and Statistics}

Data were graphed and analyzed with GraphPad Prism version 5.01 (GraphPad Software, La Jolla, CA) and SAS version 9.3 (SAS Institute Inc., Cary, NC). One-way ANOVA was used to analyze the one-factor experiment, followed by Tukey post hoc multiple-comparison test. Twoway ANOVA was used to analyze two-factor experiments followed by Bonferroni or Tukey post hoc multiple-comparison test.

\section{Results}

\section{Time Course of U50,488H-Induced KOPR Phosphorylation}

N2A-FmK6H cells were treated with $0.1 \mu \mathrm{M} \mathrm{U} 50,488 \mathrm{H}$ for $0.5,1,2,5$, and 10 minutes. $\mathrm{U} 50,488 \mathrm{H}$ very rapidly induced KOPR phosphorylation at S356/T357, T363, and S369, reaching a plateau in 30 seconds, 1 minute, and 2 minutes, respectively (Fig. 1A). Thus, for the subsequent experiments, a 2 -minute incubation time with $\mathrm{U} 50,488 \mathrm{H}$ was chosen. In addition, S356/T357 showed basal phosphorylation without $\mathrm{U} 50,488 \mathrm{H}$ treatment, which is similar to our previous finding (Chen et al., 2016).

\section{Dose-Response Relationship of U50,488H-Induced KOPR Phosphorylation}

Cells were treated with $0.01,0.1,0.3,1,3$, and $10 \mu \mathrm{M}$ $\mathrm{U} 50,488 \mathrm{H}$ for 2 minutes. U50,488H promoted KOPR phosphorylation in a dose-dependent manner at each residue (Fig. 1B). The phosphorylated $\mathrm{EC}_{50}$ values [95\% confidence intervals (CI)] for phosphorylation at S356/T357, T363 and S369 were determined to be 6.40 (95\% CI, 6.07-6.76), 6.32 (95\% CI, 5.69-6.95) and 6.63 (95\% CI, 6.46-6.79), respectively. The $\mathrm{pEC}_{50}\left(=-\log \mathrm{EC}_{50}\right)$ values (95\% confidence intervals, CI) for phosphorylation at S356/T357, T363 and S369 were determined to be 6.40 (95\% CI, 6.07-6.76), 6.32 (95\% CI, 5.69-6.95) and 6.63 (95\% CI, 6.46-6.79), respectively. There was no significant difference among the three $\mathrm{EC}_{50}$ values (one-way ANOVA followed by Tukey post hoc test, $P=0.99$ ). Based on these results, $3 \mu \mathrm{M}$ $\mathrm{U} 50,488 \mathrm{H}$ was chosen for the following experiments.

\section{Roles of Gi/o Proteins in U50,488H-Induced KOPR Phosphorylation}

Cells were pretreated with PTX followed by U50,488H incubation. PTX significantly reduced U50,488H-induced KOPR phosphorylation at S356/T357, T363, and S369 by $81 \pm 8 \%, 52 \pm 6 \%$, and $62 \pm 5 \%$, respectively (Fig. 2). The reduction in S356/T357 phosphorylation was significantly higher than T363 phosphorylation (one-way ANOVA followed by Tukey post hoc test, $P<0.05$ ). The results indicate that the activation of $\mathrm{G}_{\mathrm{i} / \mathrm{o}}$ proteins is involved in KOPR phosphorylation at each phosphosite and that pS356/T357 was more highly regulated by $\mathrm{Gi} / \mathrm{o}$ proteins than other residues.

\section{Roles of GRKs in U50,488H-Induced KOPR Phosphorylation}

GRKs are major protein kinases involved in agonistinduced GPCR phosphorylation. We found that N2A cells endogenously express GRK2, GRK3, and GRK6, but not GRK5, by Western blot with GRK2, GRK3, and panGRK4/5/6 antibodies (Fig. 3).

Knockdown of GRK2 or GRK3 decreased U50,488Hpromoted phosphorylation at S356/T357 by $77 \pm 12 \%$ and $76 \pm 16 \%$, respectively, whereas knockdown of both totally blocked phosphorylation $(115 \pm 11 \%)$. All of the values are 

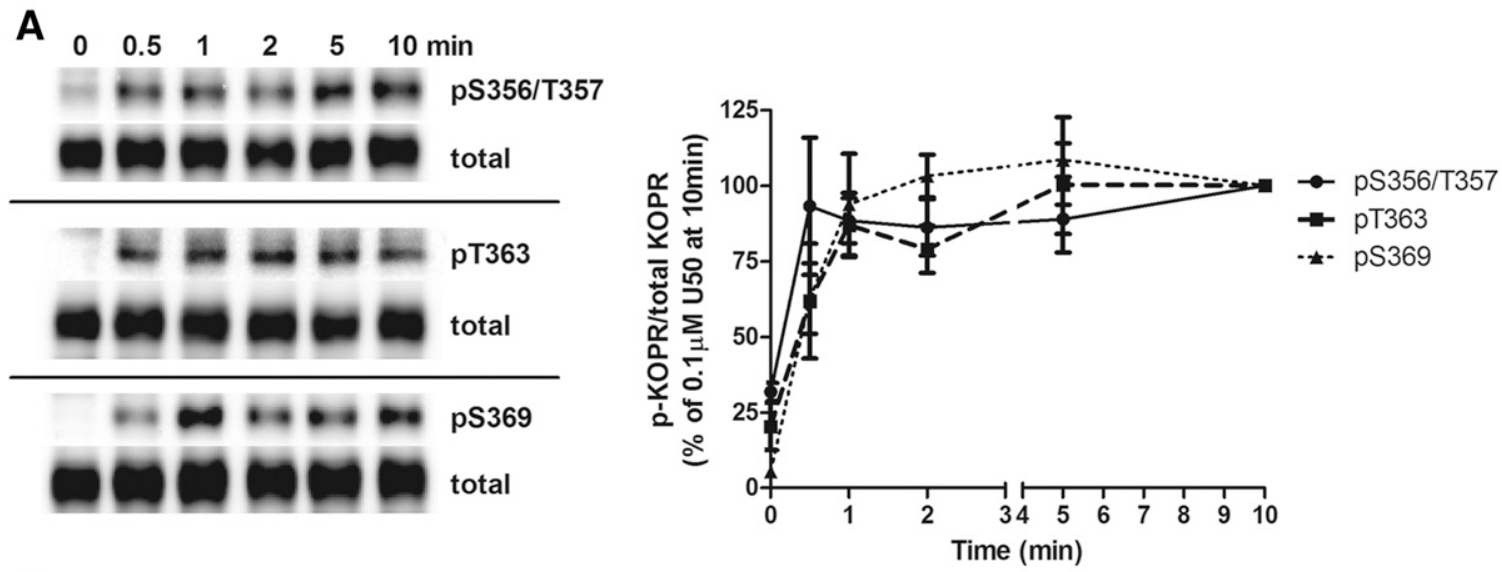

B
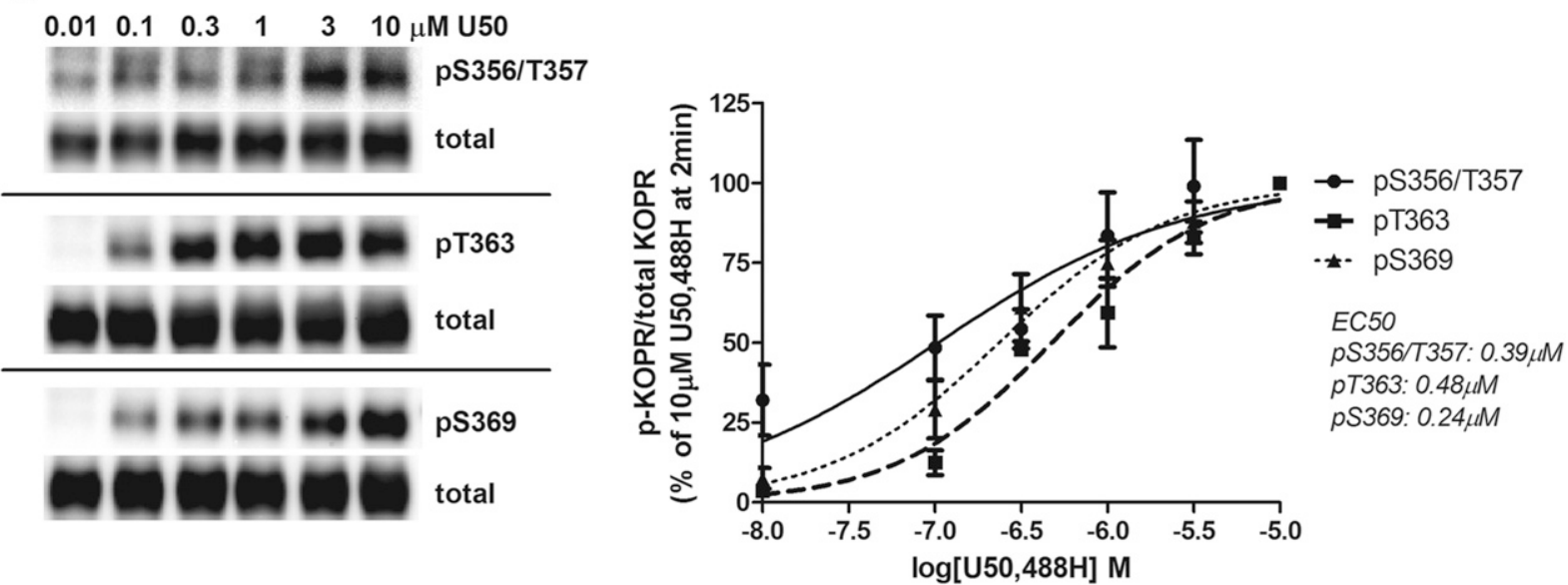

Fig. 1. Time-course and dose-response relationship of U50,488H-induced KOPR phosphorylation. N2A-FmK6H cells were treated with $0.1 \mu \mathrm{M}$ U50,488H for different durations $(0,0.5,1,2,5$, and 10 minutes) (A) or at different concentrations of U50,488H $(0.01,0.1,0.3,1,3$, and $10 \mu \mathrm{M})$ for 2 minutes $(B)$ at $37^{\circ} \mathrm{C}$. Cells were lysed with lysis buffer, and then receptors were affinity purified using Ni-NTA agarose beads. Eluted samples were subjected to Western blot using the three phospho-KOPR-specific antibodies. Membranes were stripped and blotted again for total KOPR. See Materials and Methods for details. One representative blot of each phospho-KOPR antibody is shown. Staining intensity was quantified and normalized against that of 10-minute treatment (A) or treatment with $10 \mu \mathrm{M}$ U50,488H (B). Each value is the mean \pm S.E.M. $(n=3-7)$.

the mean \pm S.E.M. $(n=3-6)$. For T363, knockdown of GRK2 reduced phosphorylation by $63 \pm 9 \%$, while knockdown of GRK3 and GRKs $2+3$ reduced by $80 \pm 5 \%$ and $79 \pm 8 \%$, respectively. For S369, knockdown of GRK2 inhibited phosphorylation by $38 \pm 3 \%$, whereas knockdown of GRK3 and GRKs $2+3$ reduced by $62 \pm 4 \%$ and $68 \pm 4 \%$, respectively (Fig. 3A). The siCtrl did not affect U50,488H-promoted phosphorylation at S356/T357, T363, and S369, compared
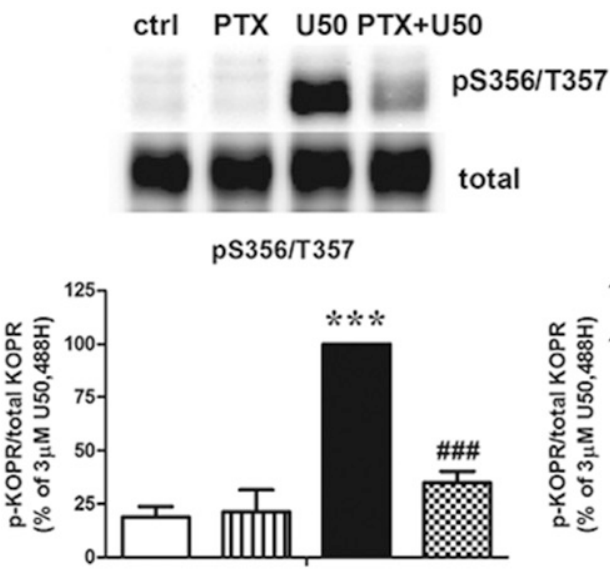

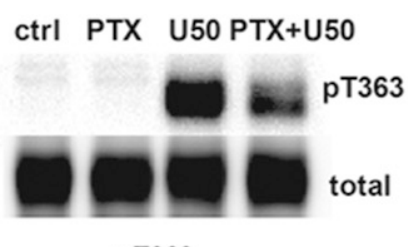

pT363
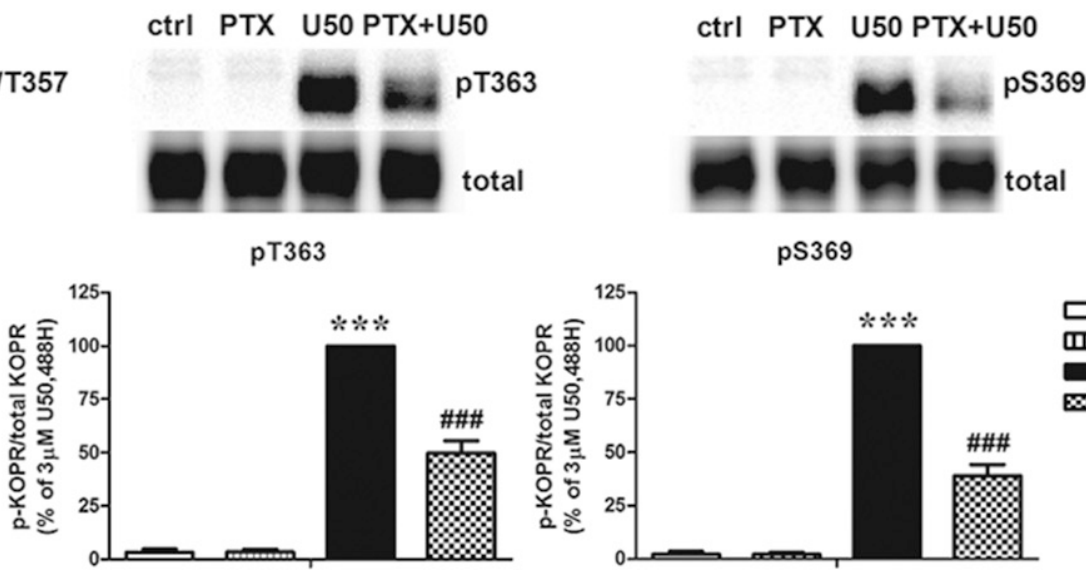

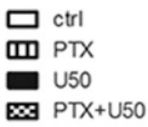

Fig. 2. Effects of PTX on U50,488H-induced KOPR phosphorylation. Cells were pretreated with $200 \mathrm{ng} / \mathrm{ml}$ PTX for 2 hours followed by a 2-minute incubation with $3 \mu \mathrm{M}$ U50,488H. Experiments were performed as described in the Fig. 1 legend. The data shown are reported as the mean \pm S.E.M. $(n=3)$ and were analyzed by two-way ANOVA followed by Bonferroni post hoc test ${ }^{* * *} P<0.001$, compared with control (ctrl) group; \#\#\#P<0.001, compared with U50,488H-treated group). 
A

$\frac{\mathrm{H}_{2} \mathrm{O}}{\text { NTF }} \frac{\begin{array}{l}\text { pS356/T357 } \\ \text { NTF siC si2 si3 si2+3 }\end{array}}{\frac{\mathrm{H}_{2} \mathrm{O}}{\text { NTF }}} \frac{\text { pT363 }}{\text { NTF siC si2 si3 si2+3 }} \frac{\mathrm{H}_{2} \mathrm{O}}{\text { NTF NTF siC si2 si3 si2+3 }}$
total

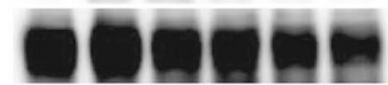

pT363
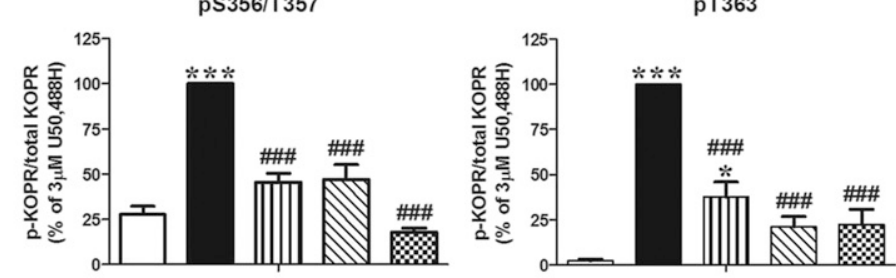

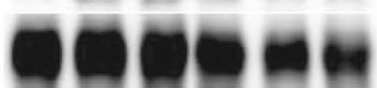

pS369
GRK3 - - -

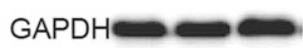

\section{B}
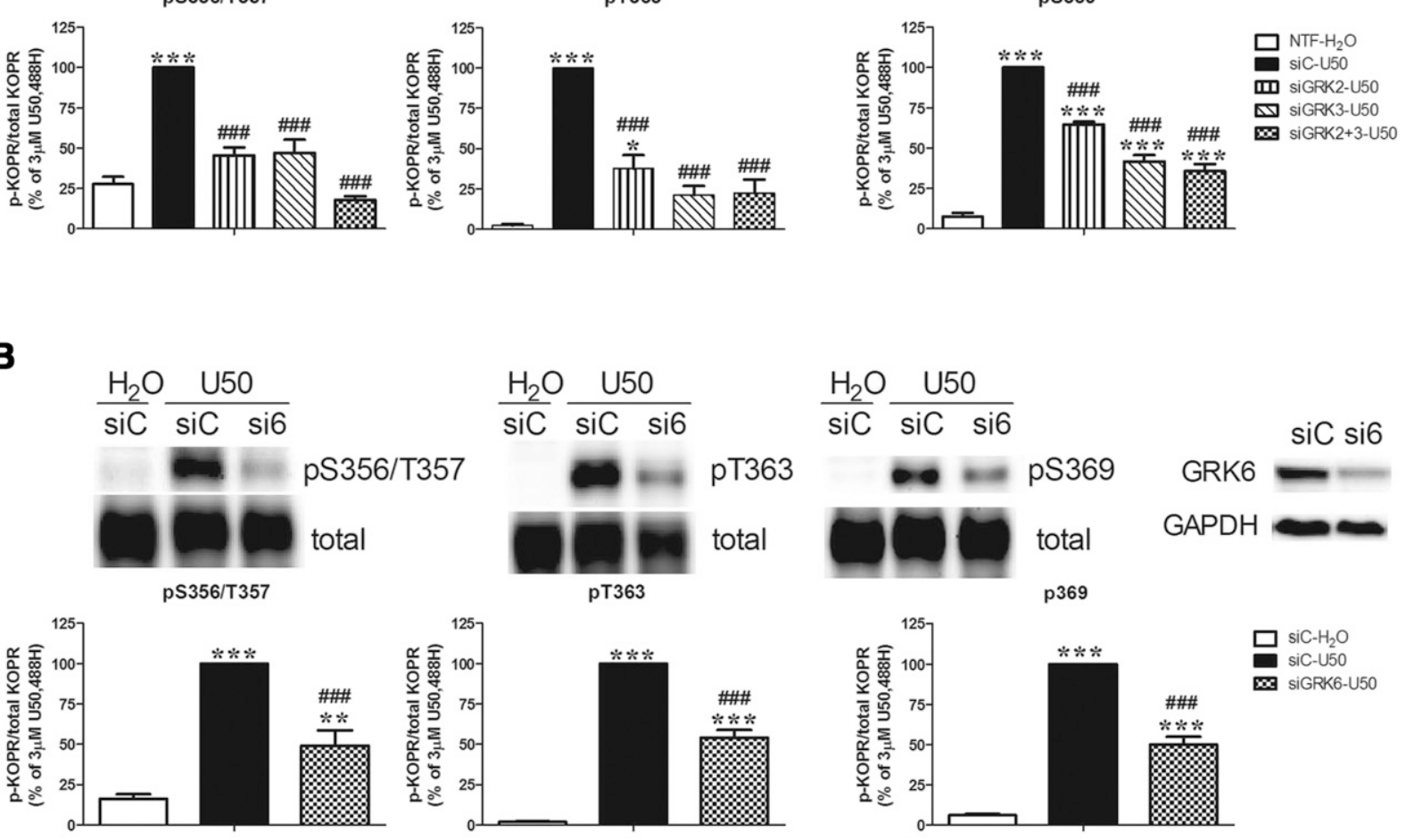

C
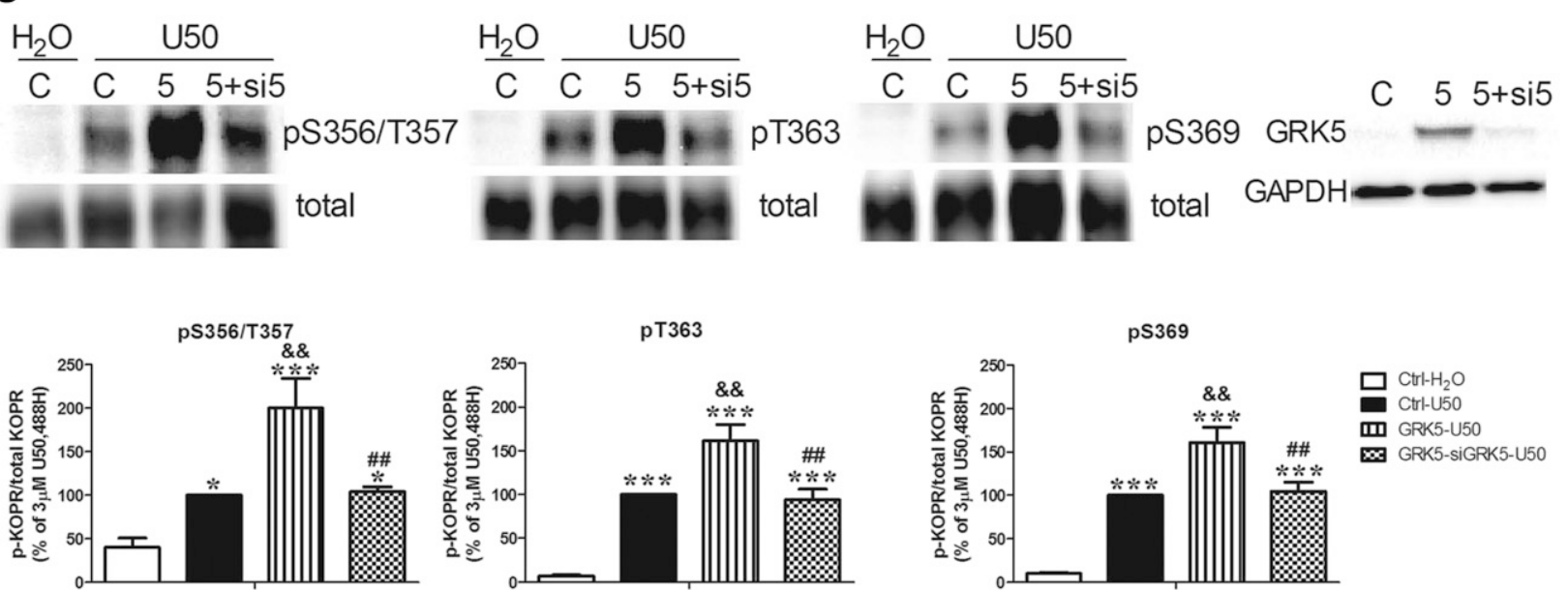

Fig. 3. Involvement of GRKs in U50,488-induced KOPR phosphorylation. (A, B) Effects of knockdown of GRK2, GRK3, and GRK6 on U50,488H-induced KOPR phosphorylation. Cells were left NTF or transfected with siCtrl (siC) or siRNAs targeting GRK2 (si2), GRK3 (si3), GRKs2+3 (si2+3), or GRK6 (si6). Two days later, cells were treated with vehicle or $3 \mu \mathrm{M}$ U50,488H for 2 minutes. Data were normalized against that of the U50,488H-treated siRNA control group (siC-U50), and values are reported as the mean \pm S.E.M. $(n=3-6)$. Knockdown of GRK2, GRK3, and GRK6 was verified by Western blot with specific antibodies. (C) Effects of GRK5 expression and expression plus knockdown on U50,488H-induced KOPR phosphorylation. Cells were cotransfected with the vector pcDNA3 and siCtrl (C), GRK5 cDNA and siCtrl (5), and GRK5 cDNA and GRK5 siRNA (5+si5) with Lipofectamine 2000. Two days later, cells were treated with vehicle or $3 \mu \mathrm{M}$ U50,488H for 2 minutes. The results were normalized against that of the U50,488H-treated vector control group (Ctrl-U50), and values are reported as the mean \pm S.E.M. $(n=6-8)$. The expression of GRK5 and the knockdown of GRK5 were validated by Western blot. Data were analyzed with one-way ANOVA followed by Tukey post hoc test $\left[* P<0.05, * * P<0.01\right.$, ${ }^{* * *} P<0.001$, compared with vehicle control group (siC- $\mathrm{H}_{2} \mathrm{O}$ ) or $\mathrm{H}_{2} \mathrm{O}$-treated control group $\left(\mathrm{Ctrl}-\mathrm{H}_{2} \mathrm{O}\right)$; \#\#P $<0.01$, \#\#\#P $<0.001$, compared with U50,488H-treated siRNA control group (siC-U50) or U50,488H-treated GRK5 overexpression group (GRK5-U50); \&\&P<0.01, compared with U50,488H-treated vector control group (Ctrl-U50)]. 


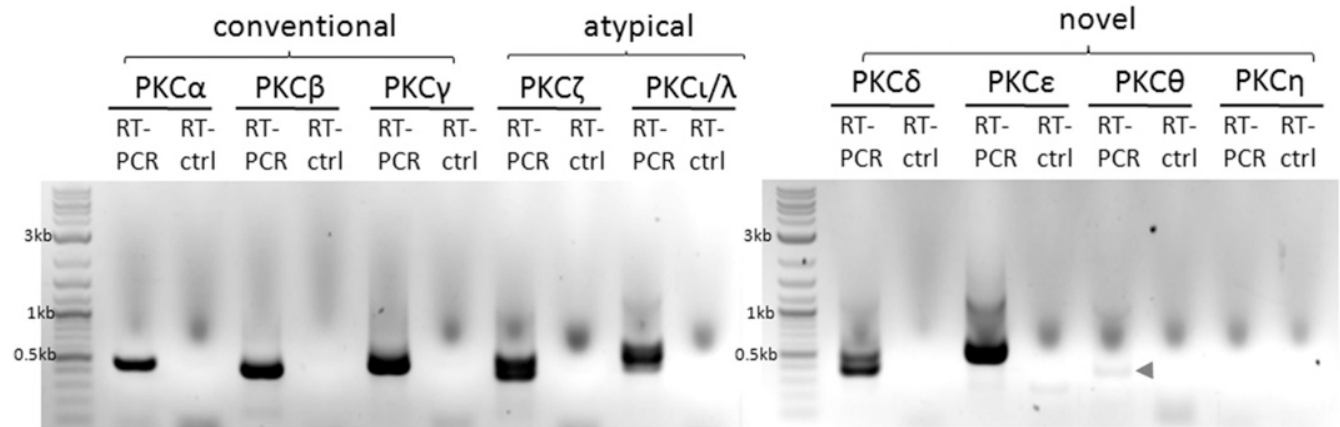

Fig. 4. Endogenous PKC isoforms in N2A cells detected with RT-PCR. N2A cells were solubilized with TRIzol reagent and then RNA was extracted. RNA was used for RT-PCR for the detection of different PKC isoforms (conventional PKCs: $\mathrm{PKC} \alpha, \mathrm{PKC} \beta$, and PKC $\gamma$; atypical PKCs: $\mathrm{PKC} \zeta$ and $\mathrm{PKC} \iota / \lambda$; novel PKCs: $\mathrm{PKC} \delta, \mathrm{PKC} \varepsilon, \mathrm{PKC} \theta$, and $\mathrm{PKC} \eta$ ). For the control, no PCR primers were added (RT-ctrl). The following PKC isoforms (predicted PCR product sizes)

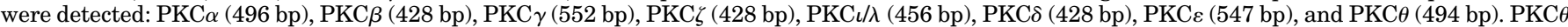
PCR product was barely detectable (arrowhead). No PKC $\eta$ PCR product was detected. The experiment was carried out twice with similar results.

with no transfection (NTF). Therefore, NTF was omitted in the subsequent experiments involving siRNA. Knockdown of GRK6 reduced U50,488H-caused KOPR phosphorylation at S356/T357, T363, and S369 by $60 \pm 11 \%, 47 \pm 5 \%$, and $53 \pm 5 \%$, respectively (Fig. 3B). These results indicate that GRK2, GRK3, and GRK6 are involved in KOPR phosphorylation at all four residues upon $\mathrm{U} 50,488 \mathrm{H}$ stimulation. GRK2 phosphorylates S356/T357 more than S369. GRK2 and GRK3 show more effects on T363 than S369. GRKs2+3 show higher involvement at S356/T357 than T363 and S369 (Fig. 7).

GRK5 was reported to participate in agonist-induced KOPR desensitization (Appleyard et al., 1999), suggesting that GRK5 is involved in KOPR phosphorylation. Since N2A cells do not express GRK5 endogenously, we examined the role of GRK5 by its expression and expression plus knockdown. The expression of GRK5 promoted higher levels of KOPR phosphorylation at S356/T357, T363, and S369 by 2-, 1.6-, and 1.6-fold, respectively, compared with the vector control. Cotransfection of GRK5 and GRK5 siRNA blocked GRK5 expression-caused KOPR phosphorylation at S356/T357, T363, and S369 by $64 \pm 9 \%, 42 \pm 8 \%$, and $38 \pm 3 \%$ (Fig. 3C). GRK5 is more involved in phosphorylating S356/T357 than S369 (Fig. 7).

Knockdown efficiency for each GRK was determined (Fig. 3 left panel). GRK2 siRNA or GRKs2 +3 siRNAs reduced GRK2 by $47 \pm 6 \%$ and $48 \pm 4 \%$, respectively, compared to control siRNA. Similarly, GRK3 siRNA or GRKs2+3 siRNAs reduced GRK3 by $48 \pm 8 \%$ and $47 \pm 7 \%$, respectively. GRK6 siRNA reduced GRK6 levels by $40 \pm 5 \%$. GRK5 siRNA reduced the overexpression level of GRK5 by $79 \pm 3 \%$. The specificity of each individual siRNA against GRK2, GRK3, GRK5, and GRK6 for its target versus other GRKs was confirmed (data not shown).

We also used the GRK2/GRK3 inhibitor compound 101 (Lowe et al., 2015) to examine the roles of GRK2 and GRK3 in U50,488H-induced KOPR phosphorylation. Compound 101 (3 $\mu \mathrm{M}$ ) inhibited U50,488H-promoted KOPR phosphorylation at S356/T357, T363, and S369 by $110 \pm 13 \%, 65 \pm 3 \%$, and $72 \pm 7 \%$, respectively (Supplemental Fig. 1). Compound 101 showed similar levels of reduction as knockdown of GRKs2+3, and both regulated S356/T357 more than T363 and S369 (Fig. 7).

Taken together, U50,488H-induced KOPR phosphorylation at S356/T357, T363, and S369 was regulated by GRK2, GRK3, GRK5, and GRK6 to different degrees (shown in Fig. 7). All four phosphoresidues are regulated concertedly by the four GRKs in that inhibition of one GRK reduces phosphorylation of all the residues, albeit to different degrees; therefore, there is no complete substitution of one GRK by the others.

\section{Roles of PKCs in KOPR Phosphorylation}

PKC was reported to be involved in homologous and heterologous phosphorylation of GPCRs, including $\mu$ opioid receptor (MOPR) and free fatty acid receptor 4 (Burns et al., 2014; Mann et al., 2015). Activation of the KOPR by agonists has been shown to stimulate PKC (Bian et al., 2000; Bohn et al., 2000). S356, T357, T363, and S369 are also PKC consensus phosphorylation sites. Thus, whether PKC regulates agonistindependent and agonist-dependent KOPR phosphorylation was characterized.

Using RT-PCR, we have found that N2A cells endogenously express the following eight $\mathrm{PKC}$ isoforms: $\mathrm{PKC} \alpha, \mathrm{PKC} \beta$, and $\mathrm{PKC} \gamma$ (conventional PKCs), $\mathrm{PKC} \zeta$ and $\mathrm{PKC} \iota / \lambda$ (atypical $\mathrm{PKCs}$ ), as well as $\mathrm{PKC} \delta, \mathrm{PKC} \varepsilon$, and a low level of $\mathrm{PKC} \theta$, but not $\mathrm{PKC} \eta$ (novel PKCs) (Fig. 4).

Roles of PKCs in Agonist-Dependent KOPR Phosphorylation. Knockdown of $\mathrm{PKC} \alpha$ or $\mathrm{PKC} \varepsilon$ by isoformspecific siRNA, which reduced each isoform level by $45 \%$ and $43 \%$, respectively, did not significantly affect U50,488Hinduced KOPR phosphorylation at any of the four sites (Supplemental Fig. 2). It is likely that siRNA knockdown of one isoform may lead to substitution by other PKC isoforms. Thus, PKC inhibitors were used subsequently to examine agonist-dependent KOPR phosphorylation.

The nonselective PKC inhibitor GF109203X (4 $\mu \mathrm{M})$ reduced U50,488H-promoted KOPR phosphorylation at S356/T357, T363, and S369 by approximately $100 \pm 1 \%$, $59 \pm 10 \%$, and $27 \pm 12 \%$, respectively (Fig. 5A). GF $109203 \mathrm{X}$ caused greater reduction in the phosphorylation of S356/T357 than T363 and S369 (Fig. 7). In addition, GF109203X lowered the basal phosphorylation level of S356/T357 (Fig. 5A). Another nonselective PKC inhibitor, CHL $(1 \mu \mathrm{M})$, significantly decreased U50,488H-promoted KOPR phosphorylation at T363 and S369 by $58 \pm 10 \%$ and $61 \pm 5 \%$, respectively, but had no effect at S356/T357 (16 $\pm 12 \%)$ without affecting basal phosphorylation (Fig. 5B). The selective $\operatorname{PKC} \alpha$ and PKC $\beta 1$ inhibitor Go6976 (100 nM) did not significantly affect U50,488H-induced KOPR phosphorylation or basal phosphorylation at all of the sites (Fig. 5C). These results indicate that different $\mathrm{PKC}$ isoforms contribute to $\mathrm{U} 50,488 \mathrm{H}-$ induced KOPR phosphorylation in a site-specific manner. 
A

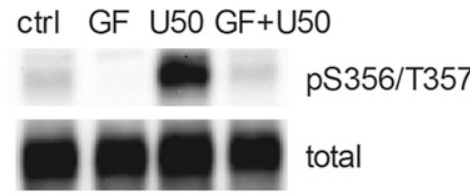

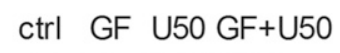

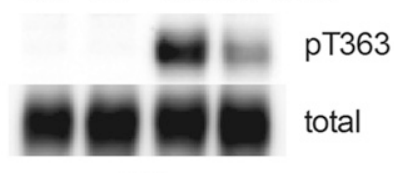

p 7363

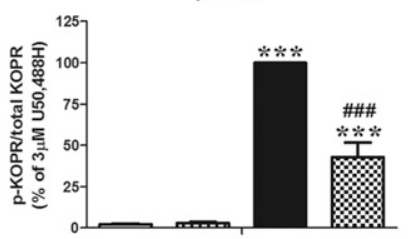

ctrl GF U50 GF+U50

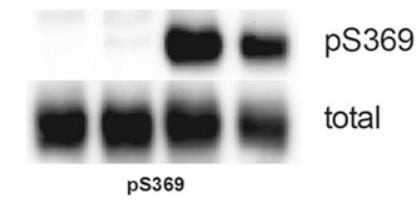

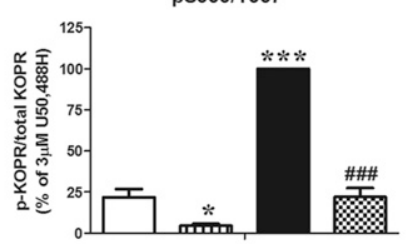

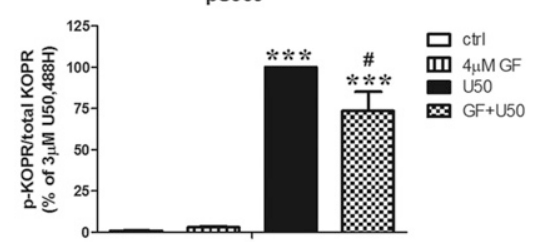

B ctrl $\mathrm{CHL} U 50 \mathrm{CHL}+\mathrm{U} 50$

ctrl $\mathrm{CHL}$ U50 CHL+U50
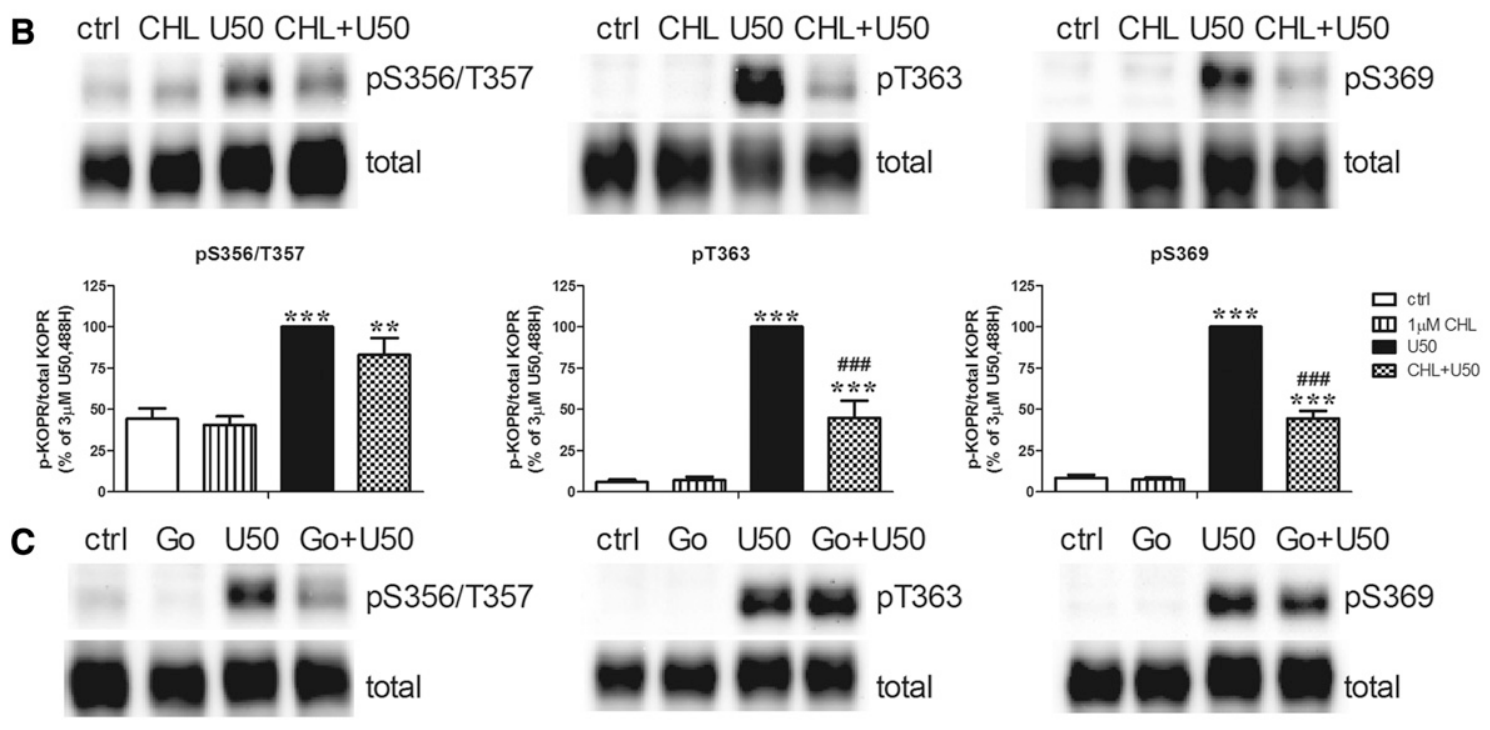

T363
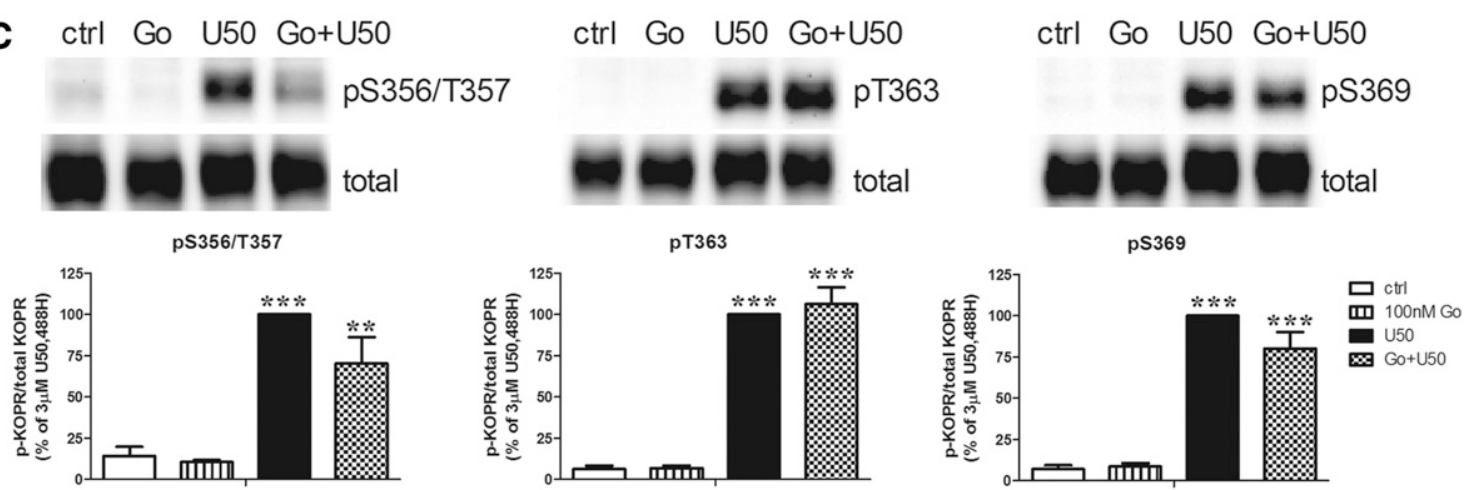

Fig. 5. Effect of PKC inhibitors on U50,488H-induced KOPR phosphorylation at S356/T357, T363, and S369. Cells were pretreated with the nonselective PKC inhibitor GF109203X (GF) $(4 \mu \mathrm{M})(\mathrm{A})$, CHL $(1 \mu \mathrm{M})(\mathrm{B})$, or the selective PKC $\alpha$ and $\beta 1$ inhibitor Go6976 (100 nM) (C) for $30 \mathrm{minutes}$ followed by $3 \mu \mathrm{M}$ U50,488H or vehicle for 2 minutes. Each point is shown as the mean \pm S.E.M. $(n=3-6)$. Data were analyzed by two-way ANOVA followed by Tukey post hoc test $\left(* P<0.05\right.$, ${ }^{* *} P<0.01$, $* * * P<0.001$, compared with control (ctrl) group; \#P<0.05, \#\#\#P<0.001, compared with U50,488H-treated group).

In addition, PKC is involved in basal KOPR phosphorylation at S356/T357.

Activation of PKCs Increased Agonist-Independent KOPR Phosphorylation. Whether PKC activation promoted agonist-independent KOPR phosphorylation was studied using the PKC activator PMA. The incubation of cells with different concentrations of PMA $(0.001,0.01,0.1,1$, and $10 \mu \mathrm{M})$ for 30 minutes enhanced KOPR phosphorylation at S356/T357, T363, and S369 in a dose-dependent manner. The $\mathrm{pEC}_{50}(95 \% \mathrm{CI})$ values of PMA in promoting phosphorylation at S356/T357, T363, and S369 were determined to be as follows: 8.18 (95\% CI 7.85-8.5), 7.50 (95\% CI 7.00-8.03), and 7.72 (95\% CI 7.55-7.89), respectively. The mean $\mathrm{EC}_{50}$ values of S356/T357, T363, and S369 phosphorylation were 6.6, 31.8 , and $19 \mathrm{nM}$, respectively (Fig. $6 \mathrm{~A}$ ). The $\mathrm{EC}_{50}$ values were significantly different between S356/T357 and T363 $(P=0.045$, one-way ANOVA followed by Tukey post hoc test). Thus, PKC activation promoted agonist-independent KOPR phosphorylation and PMA had lower potency in phosphorylating T363. Based on these results, $0.1 \mu \mathrm{M}$ PMA was used in the following experiments.

The time course and levels of PMA-promoted KOPR phosphorylation were examined and compared with those of U50,488H. Cells were treated with PMA $(0.1 \mu \mathrm{M})$ or $\mathrm{U} 50,488 \mathrm{H}(3 \mu \mathrm{M})$ for different durations $(0,1,5,15$, and 30 minutes). As shown in Figs. 6B and 6C, the time courses were different between PMA and U50,488H. PMA displayed a slower time course at S369 than U50,488H and similar phosphorylation rates at S356/T357 as U50,488H. For S356/T357, PMA promoted a much higher plateau phosphorylation level than 
A

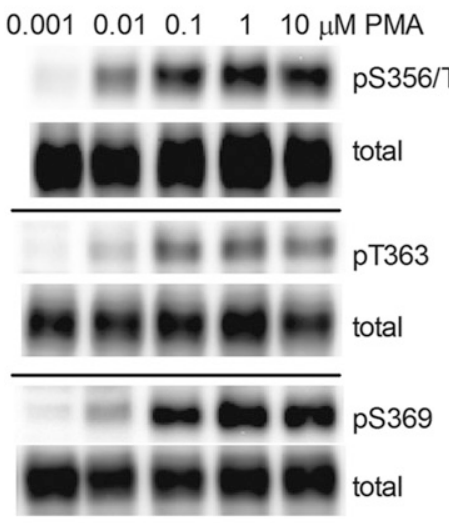

B

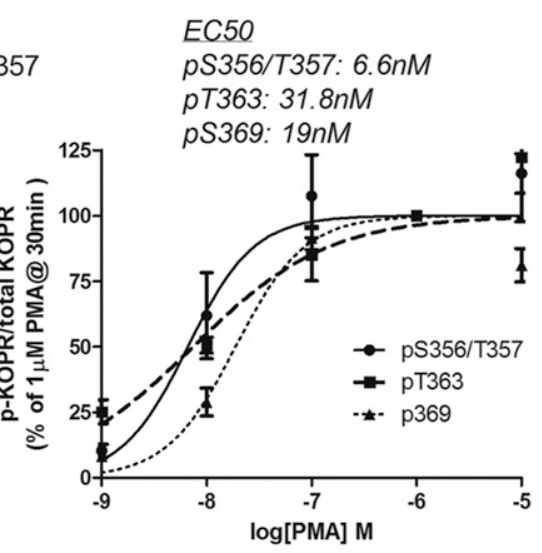

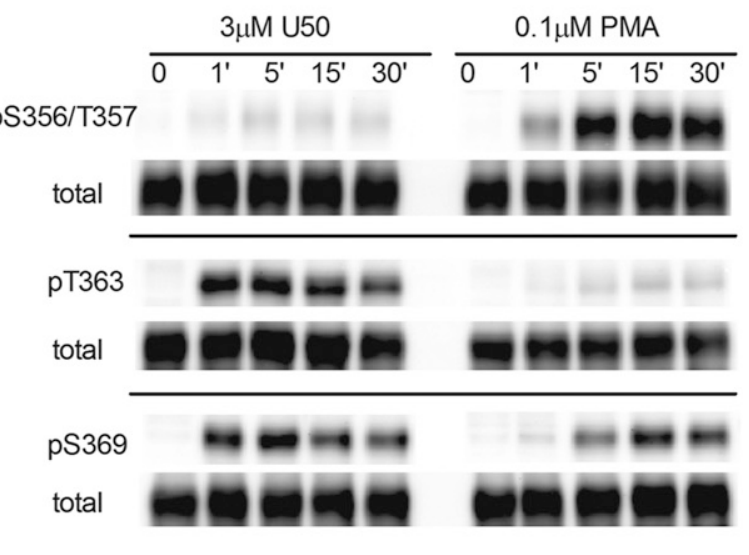

C
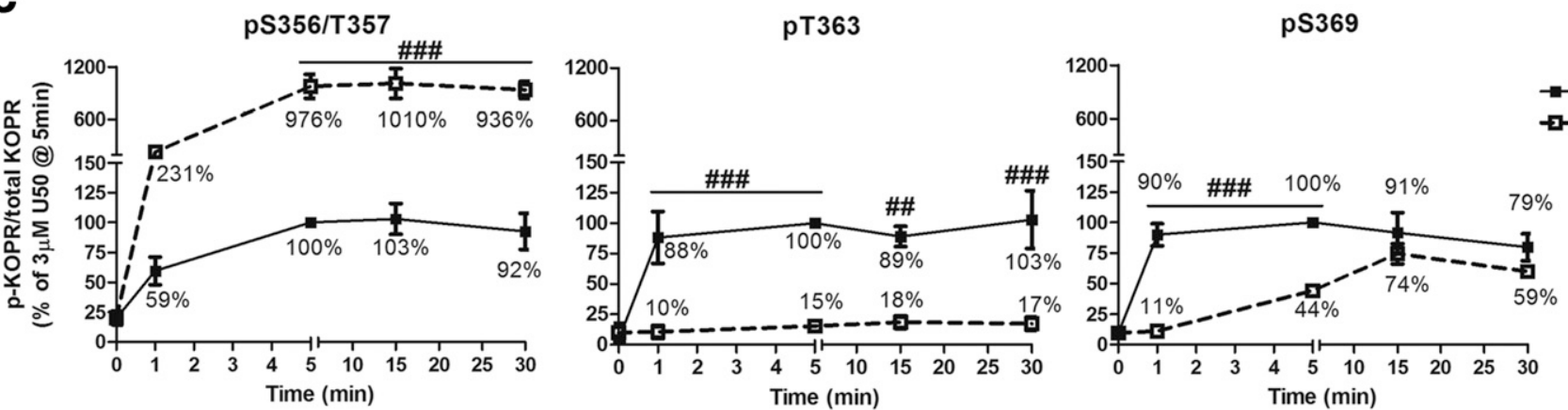

Fig. 6. Effect of PKC activation on KOPR phosphorylation. (A) Dose-response relationship of PMA-induced KOPR phosphorylation: cells were treated with different concentrations of PMA $(0.001,0.01,0.1,1$, and $10 \mu \mathrm{M})$ for 30 minutes. (B and C) Time course of PMA-induced KOPR phosphorylation and comparison with that of U50,488H: cells were incubated with $3 \mu \mathrm{M} \mathrm{U} 50,488 \mathrm{H}$ or $0.1 \mu \mathrm{M}$ PMA for $0,1,5,15$, and 30 minutes. In (A), staining intensity was normalized against that of $1 \mu \mathrm{M}$ PMA, and each value is reported as the mean \pm S.E.M. $(n=3-4)$. The mean EC $\mathrm{E}_{50}$ values of PMA in promoting phosphorylation at S356/T357, T363 and S369 are shown. In (B), there was an empty lane between U50,488H-treated and PMA-treated samples. In (C), the staining intensity in (B) was normalized against that of U50,488H at 5 minutes. Data are shown as the mean \pm S.E.M. $(n=3-4)$ and were analyzed by two-way ANOVA followed by Bonferroni post hoc test (\#\#P<0.01, \#\#P < 0.001, compared with U50,488H-treated group).

U50,488H ( 10-fold). For T363, U50,488H induced phosphorylation to greater extents than PMA ( 7-fold). For S369, U50,488H and PMA caused similar maximal phosphorylation levels. The results indicate that U50,488H and PMA showed different KOPR phosphorylation patterns and time courses.

U50,488H-induced KOPR phosphorylation at S356/T357 in Fig. 6B showed lower signals than in Fig. 1A. Since PMAinduced KOPR phosphorylation at S356/T357 yielded very high signals (Fig. 6B), the U50,488H-induced pS356/T357 signals in Fig. $6 \mathrm{~B}$ were captured with shorter exposure time to prevent the PMA signals from being overexposed. Similarly, PMA-induced KOPR phosphorylation at pT363 in Fig. 6B showed a weaker signal than that in Fig. 6A (see the signals at $0.1 \mu \mathrm{M}$ and 30 minutes) because they were captured with a shorter exposure time to prevent the U50,488H signals in Fig. 6B from overexposure.

\section{Phosphorylation Patterns: Regulation of U50,488H-Induced Site-Specific Phosphorylation by Distinct Protein Kinases}

Figure 7 summarizes the involvements of various kinases in U50,488H-promoted KOPR phosphorylation at the four residues. Different residues were regulated to different degrees by multiple protein kinases. For GRKs, although the four GRK isoforms regulated all of the phosphoresidues on the KOPR, each had different degrees of involvement in phosphorylating the four sites. GRK2 phosphorylated S356/T357 more than S369, and T363 more than S369 (S356/T357 > S369 and T363 > S369). GRK3 showed more effect on T363 than S369 (T363 > S369). GRKs2+3 caused higher phosphorylation of S356/T357 than T363 and S369 (S356/T357 > T363 and S356/T357 > S369). GRK5 caused phosphorylation of S356/T357 > S369. GRK6 is similarly involved in phosphorylating the four residues $(\mathrm{S} 356 / \mathrm{T} 357=\mathrm{T} 363=\mathrm{S} 369)$. For PKC, GF109203X suppressed U50,488H-induced phosphorylation of S356/T357 more than T363 and S369 (S356/T357 > T363 and S356/T357 > S369). CHL inhibited the phosphorylation of T363 and S369 to similar extents (T363 = S369) but had no effect on the phosphorylation of S356/T357. Go6976 had no effect on KOPR phosphorylation at S356/T357, T363, and S369. Whether differences in protein kinase-mediated KOPR phosphorylation led to diverse functional outputs was examined below.

\section{Effects of Protein Kinase-Mediated KOPR Phosphorylation on Cellular Functions}

GPCR phosphorylation is the initial step in desensitizing G protein-mediated signaling as well as in initiating $\beta$-arrestindependent signaling and receptor internalization. Thus, we examined the effect of protein kinase-mediated KOPR phosphorylation on receptor internalization (Fig. 8) and the downstream signaling (Fig. 9). 


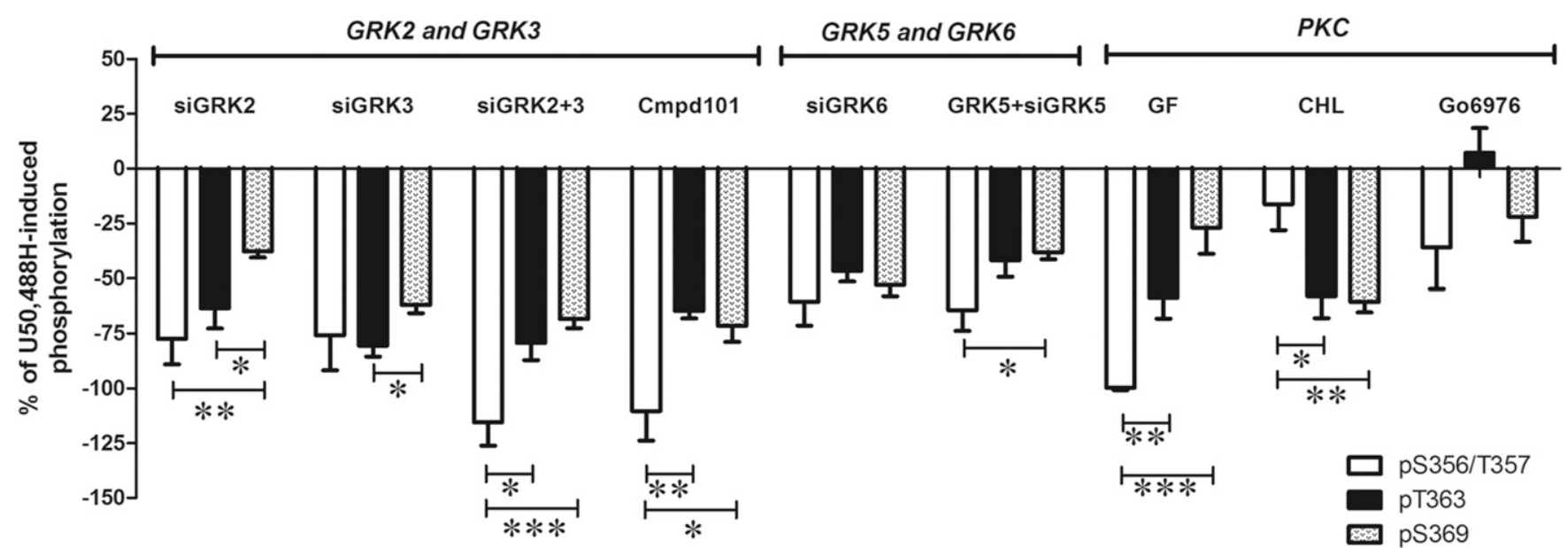

Fig. 7. Regulation of U50,488H-induced KOPR phosphorylation at S356/T357, T363, and S369 by protein kinases. This figure summarizes and compares the percentage of reduction by inhibitors and GRK siRNAs of U50,488H-induced KOPR phosphorylation at all the four phosphosites. The value was calculated according to the equation: \% reduction $=\{[($ inhibitor or siRNA $+\mathrm{U} 50,488 \mathrm{H})-\mathrm{U} 50,488 \mathrm{H}] / \mathrm{U} 50,488 \mathrm{H}\} \times 100 \%$. Data were analyzed by two-way ANOVA followed by Tukey-Kramer post hoc test $\left(* P<0.05,{ }^{*} P<0.01, * * * P<0.001\right)$.

Effects of Agonist-Dependent and -Independent KOPR Phosphorylation on KOPR Internalization. Knockdown of GRKs2+3 or GRK6 decreased U50,488H-induced KOPR internalization from $\sim 60 \%$ to $\sim 30 \%$ and $\sim 40 \%$, respectively (Fig. 8A), indicating that GRK2/3 and GRK6 are involved in U50,488H-induced KOPR internalization. The inhibition of PKC by GF109203X or CHL did not affect U50,488H-induced internalization (Fig. 8B). Therefore, GRK-mediated, but not PKCmediated, KOPR phosphorylation causes U50,488H-induced internalization. In addition, PMA induced $\sim 12 \%$ KOPR internalization, which is much lower than with U50,488H (Fig. 8B).

Comparison between Fig. 8, A and B showed that U50,488H induced internalization of $60 \%$ and $43 \%$ of cell surface KOPR, respectively. The different extents of internalization are likely due to the influence of transfection on cells. The results presented in Fig. 8A involved cells with siRNA transfection, whereas those in Fig. 8B were from cells treated with different compounds without transfection. Transfection with Lipofectamine 2000, which affects plasma membranes, may affect receptor internalization. This is a limitation of using the transfection procedures.

Roles of Protein Kinase-Mediated KOPR Phosphorylation in U50,488H-Induced ERK1/2 Signaling. KOPR activation has been shown to activate ERK1/2 (Belcheva et al., 1998; Bruchas et al., 2006). The incubation of cells with $\mathrm{U} 50,488 \mathrm{H}$ for different durations $(1,2,5,10,20$, and 30 minutes and 1,2,3, and 4 hours) increased phosphorylated ERK1/2 levels with a peak at 5 minutes (defined as $100 \%$ ), followed by a decline to about $40-50 \%$ and then sustained stimulation at $40-50 \%$ for up to 4 hours (Fig. 9A).

The roles of Gi/o proteins, GRKs, and $\beta$-arrestins in U50,488Hinduced ERK1/2 activation at 5 minutes and 1 hour were examined. PTX pretreatment blocked U50,488H-induced ERK1/2 phosphorylation at 5 minutes and 1 hour (Fig. 9B), indicating that both are $\mathrm{G}$ protein-dependent. Thus, in N2A cells, there is no differentiation between the early phase and late phase of ERK1/2 activation, as shown in astrocytes by McLennan et al. (2008). Knockdown of GRKs2+3 or GRK6
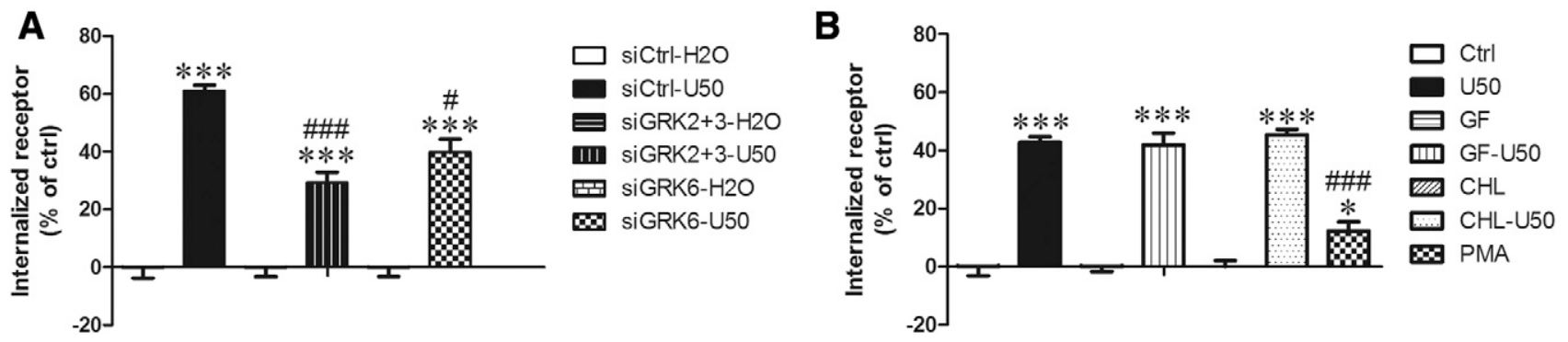

Fig. 8. Roles of GRKs and PKC in KOPR internalization. (A) GRKs mediated U50,488H-induced KOPR internalization. Cells were transfected with siCtrl or siRNAs targeting GRKs2+3 (siGRKs2+3) or GRK6 (siGRK6). Two days later, cells were treated with vehicle or $3 \mu \mathrm{M}$ U50,488H for 30 minutes. Cells were collected with $1 \mathrm{mM}$ EDTA in PBS and then washed three times with $0.1 \%$ bovine serum albumin in PBS for 10 minutes at $4^{\circ} \mathrm{C}$. Receptor internalization was determined using $\left[{ }^{3} \mathrm{H}\right]$ diprenorphine binding to total and cell surface KOPR in cells as described in the Materials and Methods. Internalized receptors are presented as the percentage of the U50,488H-treated group over that of the water-treated group. The data were shown the mean \pm S.E.M. $(n=3)$ and analyzed with two-way ANOVA followed by Bonferroni post hoc test [*** $P<0.001$, compared with vehicle control group (siCtrl- $\mathrm{H}_{2} \mathrm{O}$ ); $\# P<0.05$, $\# \# \# P<0.001$, compared with U50,488H-treated siRNA control group (siCtrl-U50)]. (B) PKC promoted agonist-independent KOPR internalization but was not involved in U50,488H-dependent KOPR internalization. Cells were treated with $4 \mu \mathrm{M}$ GF109203X (GF) or $1 \mu \mathrm{M}$ CHL for 30 minutes and then treated with water or $3 \mu \mathrm{M}$ U50,488H for 30 minutes. Some cells were treated with $0.1 \mu \mathrm{M}$ PMA for 30 minutes. Cells were treated as described above. Results are shown as the mean \pm S.E.M. $(n=3)$. Data for PKC inhibitor-treated groups were analyzed by two-way ANOVA followed by Bonferroni post hoc test $(* * * P<0.001$, compared with control-treated group). The data for PMA were analyzed with one-way ANOVA followed by Tukey post hoc test [*P<0.05; ***P<0.001, compared with control group (Ctrl); \#\#P < 0.001, compared with U50,488H-treated group (U50)]. 
A

0 1' 2' 5' 10' 20' 30' 1h 2h 3h 4h $3 \mu \mathrm{M}$ U50

ニーニーニニニニニニこ

こニニニニニニニニニ ERK
B

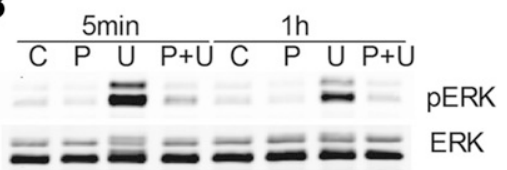

C

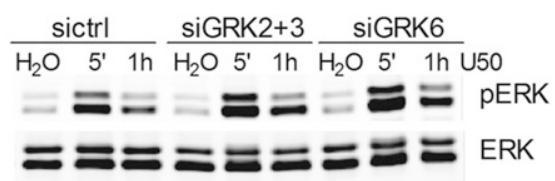

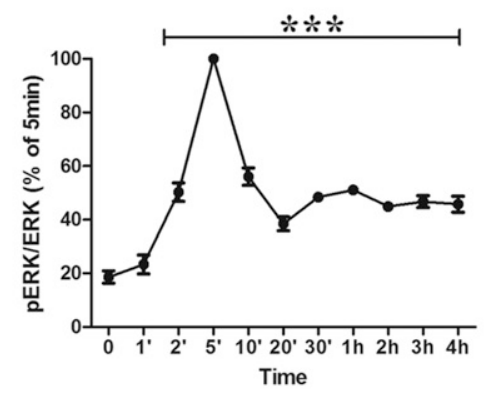

D
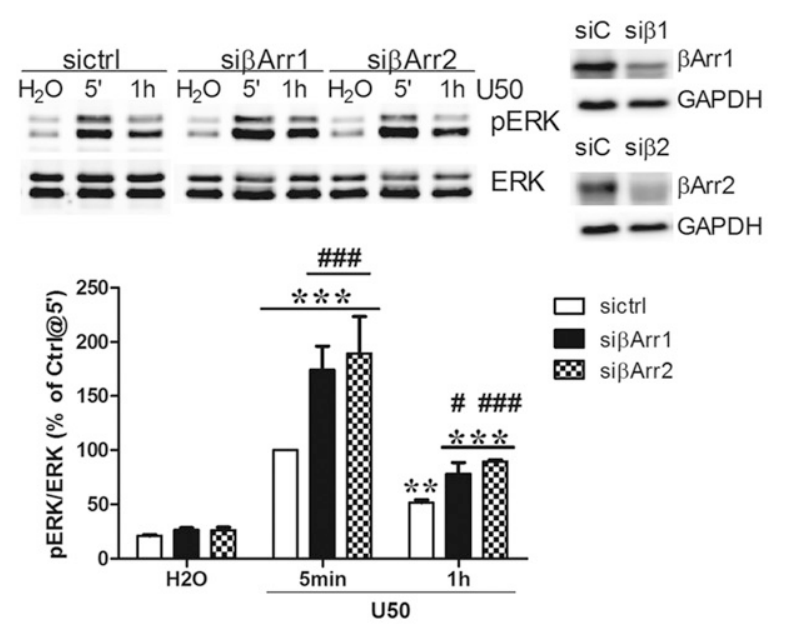
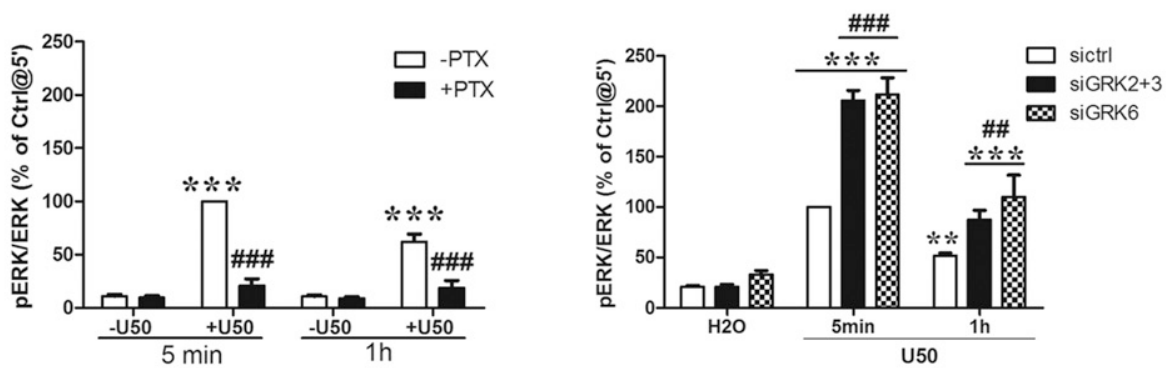

E
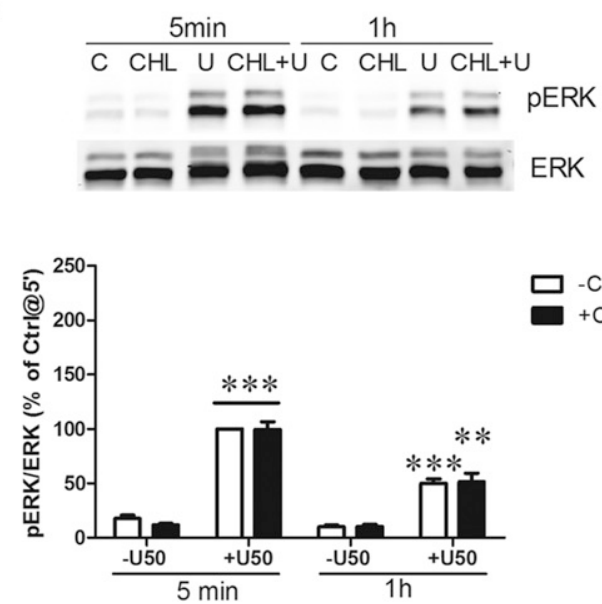

Fig. 9. U50,488H-induced ERK1/2 phosphorylation: roles of G proteins, GRKs, and $\beta$-arrestins. (A) Cells were treated with $3 \mu \mathrm{M}$ U50,488H for different periods of time $(0,1,2,5,10,20$, and 30 minutes and 1, 2, 3, and 4 hours). (B) Cells were pretreated with $200 \mathrm{ng} / \mathrm{ml}$ PTX (P) for 2 hours followed by $3 \mu \mathrm{M}$ $\mathrm{U} 50,488 \mathrm{H}$ (U) for 5 minutes or 1 hour. (C and D) Cells were transfected with siCtrl (siC) or siRNAs targeting GRK2 and GRK3 (si2+3), GRK6 (si6), $\beta$-arrestin 1 ( $\mathrm{si} \beta 1$ or si $\beta$ Arr 1 ), or $\beta$-arrestin 2 ( $\mathrm{si} \beta 2$ or si $\beta$ Arr2). Two days later, cells were treated with $\mathrm{H}_{2} \mathrm{O}$ or $3 \mu \mathrm{M}$ U50,488H for 5 minutes or 1 hour. (E) Cells were pretreated with $1 \mu \mathrm{M} \mathrm{CHL}$ for 30 minutes and then incubated with $\mathrm{H}_{2} \mathrm{O}$ or $3 \mu \mathrm{M}$ U50,488H for 5 minutes or 1 hour. ERK1/2 phosphorylation was determined as described in Materials and Methods. Data shown are the mean \pm S.E.M. $(n=3-4)$. (A) Data were analyzed by one-way ANOVA followed by Tukey post hoc test (*** $P<0.001$, compared with time zero group). (B) Data were analyzed by two-way ANOVA followed by Bonferroni post hoc test $(* * * P<0.001$, compared with vehicle-treated group; \#\#\#P<0.001, compared with U50,488H-treated group). (C) Data were analyzed by two-way ANOVA followed by Bonferroni post hoc test

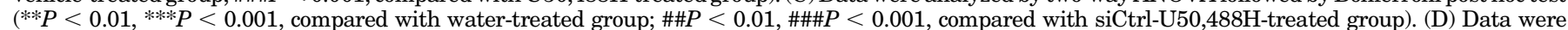
analyzed by two-way ANOVA followed by Bonferroni post hoc test $\left(* * P<0.01,{ }^{* * *} P<0.001\right.$, compared with water-treated group; \#\#\#P<0.001, compared with sictrl-U50,488H-treated group at 5 minutes) and by $t$ test for 1 -hour U50,488H treatment between sictrl and $\operatorname{si} \beta$-arrestin (\#P<0.05, \#\#\#P<0.001). (E) Data were analyzed by two-way ANOVA followed by Bonferroni post hoc test $(* * P<0.01$, *** $P<0.001$, compared with vehicle-treated group).

enhanced ERK1/2 activation at 5 minutes and 1 hour (Fig. 9C). Agonist-caused GPCR phosphorylation leads to $\beta$-arrestin recruitment, so the role of $\beta$-arrestins in U50,488H-induced ERK1/2 activation was examined. Knockdown of $\beta$-arrestin 1 or $\beta$-arrestin 2 , which reduced $\beta$-arrestin 1 or $\beta$-arrestin 2 by $38 \pm 5 \%$ or $45 \pm 6 \%$, respectively, increased ERK1/2 activation at 5 minutes and 1 hour (Fig. 9D), similar to the GRK knockdown results. These results indicate that U50,488H-induced ERK1/2 phosphorylation is G protein-dependent, but not GRK- or $\beta$-arrestin-, dependent. Instead, GRK-mediated KOPR phosphorylation followed by $\beta$-arrestin recruitment is involved in the desensitization of $\mathrm{G}$ protein-mediated ERK1/2 signaling.

We also examined whether U50,488H-induced PKCmediated KOPR phosphorylation regulated desensitization of $\mathrm{G}$ protein-mediated ERK1/2 activation. The treatment of cells with CHL $(1 \mu \mathrm{M})$ did not affect U50,488H-induced ERK1/2 activation at 5 minutes and 1 hour (Fig. 9E), demonstrating that $\mathrm{PKC}$ is not involved. Thus, GRK-mediated, but not PKC-mediated, KOPR phosphorylation plays a role in the desensitization of $\mathrm{G}$ protein-mediated ERK1/2 signaling.

\section{Discussion}

Our studies have shown that $\mathrm{Gi} / \mathrm{o}_{\alpha}$ proteins and multiple protein kinases (GRK2, GRK3, GRK5, GRK6, and PKC) are involved in agonist (U50,488H)-induced KOPR phosphorylation, and that PKC also promotes agonist-independent KOPR phosphorylation. GRK-mediated, but not PKC-mediated, agonistdependent KOPR phosphorylation is involved in KOPR internalization and desensitization of $\mathrm{G}$ protein-dependent ERK1/2 phosphorylation. PMA-induced agonist-independent KOPR phosphorylation results in a lower extent of receptor 
internalization than U50,488H. KOPR is phosphorylated by U50,488H (GRK and PKC mediated) and PMA (PKC activation) in distinct phosphorylation patterns, leading to differential KOPR functional regulations (internalization and desensitization). To the best of our knowledge, this is the first demonstration that PKC and GRK6 are involved in KOPR phosphorylation and that different KOPR phosphorylation patterns cause distinct functional consequences.

Multiple Protein Kinases Induced KOPR Phosphorylation and the Barcode Hypothesis. The "barcode" hypothesis postulates that different kinases phosphorylate distinct residues of GPCRs, leading to distinct functional outcomes (Nobles et al., 2011; Butcher et al., 2012). For example, upon agonist treatment, the M3 muscarinic receptor phosphorylation is involved in desensitization of the phospholipase $\mathrm{C}$ pathway and receptor internalization, whereas casein kinase $1 \alpha-$ and casein kinase $2 \alpha$-mediated phosphorylation impacts on ERK1/2 and Jun kinase pathways, respectively (for review, see Butcher et al., 2012). In this study, after U50,488H treatment, GRKmediated, but not PKC-mediated, phosphorylation is involved in U50,488H-induced internalization and desensitization of ERK1/2 signaling. PKC-activated agonist-independent KOPR phosphorylation caused lower degrees of internalization compared with U50,488H. Thus, it is likely that fine tuning of phosphorylation of the four KOPR residues by multiple protein kinases (GRKs and PKC isoforms) via different phosphorylation patterns (residues and levels) provides a regulatory mechanism contributing to diverse cellular outcomes.

Interestingly, all four GRK isoforms (GRK2, GRK3, GRK5, and GRK6) are involved in KOPR phosphorylation to different degrees at all the four residues. GRK2 and GRK5 phosphorylate S356/T357 more than S369. GRK2 and GRK3 have more effects on T363 than S369. GRKs2+3 show more involvement in phosphorylating S356/T357 than T363 and S369. GRK6 phosphorylates all of the residues to similar degrees. It is noteworthy that siRNA knockdown of GRK2, 3, or 6 alone greatly decreased U50,488H-promoted KOPR phosphorylation, suggesting that concerted activities of all three endogenous GRKs are required to fully phosphorylate KOPR. Similarly, knockdown of GRKs2+3 or GRK6 profoundly increased U50,488H-induced ERK1/2 phosphorylation and largely attenuated U50,488H-caused internalization, demonstrating that combined effects of GRK2/GRK3 and GRK6 are needed for full desensitization and internalization of the receptor. GRKs have been reported to be regulated by PKC. PKC phosphorylates GRK2 and GRK5, leading to GRK2 activation, but GRK5 inhibition (Chuang et al., 1995; Winstel et al., 1996; Pronin and Benovic, 1997). N2A cells endogenously express GRK2, but not GRK5. The possibility cannot be excluded that the effects of PKC inhibition are in part due to GRK2 inhibition, resulting in reduced KOPR phosphorylation. On the other hand, because compared with U50,488H, PMA induced much higher S356/T357 phosphorylation and much lower T363 phosphorylation and PMA promoted much slower S369 phosphorylation, it is unlikely that the actions of PMA occurred through GRK2 activation.

Different cells or tissues are likely to express different populations and levels of GRKs, PKC isoforms, and other protein kinases, leading to distinct phosphorylation patterns and functional consequences. For example, U50,488H did not cause internalization of rKOPR in Chinese hamster ovary cells (Li et al., 1999) but did so in human embryonic kidney 293 cells
(McLaughlin et al., 2003). Therefore, GPCR phosphorylation shows cell specificity and tissue specificity, leading to recruitment of different levels of $\beta$-arrestins, activation of different downstream signal pathways and ultimately unique physiological and pharmacological responses (Tobin, 2008; Tobin et al., 2008).

Role of PKC in Basal and U50,488H-Induced KOPR Phosphorylation. U50,488H-induced KOPR phosphorylation was inhibited to different degrees by GF109203X at all the four residues (Fig. 5A) and by CHL at two residues (T363 and S369) (Fig. 5B), but not by Go6976 (Fig. 5C). GF109203X inhibits all PKC isoforms (conventional, novel, and atypical PKCs) (Martiny-Baron et al., 1993; Hofmann, 1997), whereas CHL affects two PKC subfamilies (conventional and novel PKCs) (Herbert et al., 1990). Go6976 is a selective PKC $\alpha$ and PKC $\beta 1$ inhibitor. Thus, two inhibitors reduced KOPR phosphorylation at the same residues to different degrees, which is likely due to their diverse effects on PKC isoforms and different extents of inhibition on each isoform. In addition, the findings that GF109203X, but not CHL and Go6976, reduced basal KOPR phosphorylation at S356/T357 indicate that atypical PKC isoforms play roles in basal S356/T357 phosphorylation. PKC has been reported to be involved in basal phosphorylation at S363 of MOPR and morphine-dependent MOPR phosphorylation (Johnson et al., 2006; Hull et al., 2010; Chen et al., 2013).

PKC-Mediated Agonist-Independent KOPR Phosphorylation. PMA, which activates conventional and novel PKCs, promoted KOPR phosphorylation at S356/T357, T363, and S369 (Fig. 6). PKC-mediated agonist-independent KOPR phosphorylation may be involved in heterologous desensitization of KOPR. PKC was reported to promote agonist-independent phosphorylation of other GPCRs, such as MOPR (Illing et al., 2014) and FFA4 receptor (Burns et al., 2014).

Role of Gi/o Proteins in U50,488H-Induced KOPR Phosphorylation. Pretreatment with PTX decreased U50,488H-stimulated KOPR phosphorylation at S356/T357, T363, and S369 (Fig. 2), indicating the involvement of Gi/o proteins. The role of $\mathrm{Gi} / \mathrm{o}$ proteins is likely related to their regulation of GRKs and PKC. After G protein activation by GPCRs, GRK2 and GRK3 are recruited to plasma membranes by association with $\mathrm{G}_{\beta \gamma}$ proteins. PTX inhibits the activation of $\mathrm{Gi} / \mathrm{o}_{\alpha}$ proteins and thus blocks the release of $\mathrm{G}_{\beta \gamma}$ subunits, resulting in no activation of GRK2 and GRK3. In addition, PKC activation is downstream of KOPR and G protein activation (Bohn et al., 2000; Belcheva et al., 2005). Thus, inactivation of Gi/o proteins may also impair PKC-mediated KOPR phosphorylation after U50,488H treatment.

Effects of Agonist-Dependent and -Independent KOPR Phosphorylation on Receptor Internalization. Our results that GRK2/GRK3 and GRK6, but not PKC, are involved in U50,488H-induced KOPR internalization (Fig. 8) are consistent with those of previous reports. GRK2 and GRK3 are involved in U50,488H-induced internalization of the human and the rKOPR ( $\mathrm{Li}$ et al., 1999; Schulz et al., 2002; McLaughlin et al., 2003). The PKA/PKC inhibitor staurosporine did not inhibit U50,488H-induced rKOPR internalization (McLaughlin et al., 2003).

We previously showed that U50,488H caused a higher phosphorylation level at S356/T357, T363, and S369 and produced more double and triple phosphorylation compared with etorphine. U50,488H induced KOPR internalization, but etorphine did not, indicating that above-threshold KOPR phosphorylation is required for KOPR internalization and 
that higher-order KOPR phosphorylation is perhaps more important for KOPR internalization (Chen et al., 2016). Knockdown of GRKs2+3 affected all KOPR phosphoresidues more than PKC inhibitors (Fig. 7). Thus, U50,488Hpromoted PKC-mediated KOPR phosphorylation may be below the threshold necessary for internalization or cause lower levels of higher-order KOPR phosphorylation. PMA induced a low level of KOPR internalization, indicating that PMA promoted an above-threshold KOPR phosphorylation or higher levels of higher-order KOPR phosphorylation to trigger internalization.

Compared with U50,488H, PMA promoted much higher S356/T357 phosphorylation, much lower T363 phosphorylation, and a similar level of S369 phosphorylation. In addition, PMA-promoted KOPR phosphorylation at S369 reached plateaus at a later time than $\mathrm{U} 50,488 \mathrm{H}$ (Fig. 5). Another possibility for lower internalization by PMA is phosphorylation rates. Thus, spatial and temporal regulations on KOPR phosphorylation may contribute to different cellular outcomes.

In summary, agonist-dependent (GRK- and PKC-mediated) and agonist-independent (PKC activation) KOPR phosphorylation yield different levels and rates of phosphorylation at each residue, leading to different internalization outputs.

Role of Receptor Phosphorylation in KOPR Signaling. Knockdown of GRKs increased U50,488H-induced ERK1/2 activation, suggesting that GRK-mediated KOPR phosphorylation desensitizes agonist-induced G proteindependent ERK1/2 signaling. These results are similar to those of Doll et al. (2012) on the MOPR. In contrast, PKCmediated KOPR phosphorylation is not involved in this desensitization. Taken together, GRK-mediated and PKCmediated KOPR phosphorylation showed distinct regulations for desensitization of $\mathrm{G}$ protein-dependent signaling. One possible explanation is that GRK-, but not PKC-, mediated KOPR phosphorylation reaches a level above the threshold or more higher-order phosphorylation to cause desensitization.

Our findings that GRKs and $\beta$-arrestins desensitized U50,488H-induced Gi/o-mediated ERK1/2 activation are consistent with those of Chavkin and colleagues (Appleyard et al., 1999) that U69,593-induced rKOPR desensitization was regulated by GRK3, GRK5, and $\beta$-arrestin 2 .

Our result that $\mathrm{PKC}$ was not involved in $\mathrm{U} 50,488 \mathrm{H}$-induced ERK1/2 activation in N2A cells is different from the observations of Coscia and colleagues (Bohn et al., 2000; Belcheva et al., 2005) in C6 glioma and astrocytes. The differences are likely due to cell systems used.

Our observation that U50,488H-induced ERK1/2 phosphorylation was $\mathrm{G}$ protein-dependent without $\beta$-arrestin involvement in N2A cells is similar to those of Jamshidi et al. (2015) in peripheral sensory neurons. In contrast, in astrocytes, the activation of the KOPR by U69,593 yielded the following biphasic ERK1/2 activations: G protein-dependent activation in the early phase (at 5 minutes) and $\beta$-arrestin 2 -dependent activation in the late phase (at 30 minutes and 2 hours) (McLennan et al., 2008). The differences may be due to the different cell systems used.

\section{Acknowledgments}

The authors thank Dr. Jeffrey Benovic and Dr. Walter Koch for providing reagents and Dr. Barrie Ashby for critical reading of the manuscript.

\section{Authorship Contributions}

Participated in research design: Chiu, Chen, Schulz, and Liu-Chen. Conducted experiments: Chiu and Chen.

Contributed new reagents or analytic tools: Schulz.

Performed data analysis: Chiu, Chen, Yu, and Liu-Chen.

Wrote or contributed to the writing of the manuscript: Chiu and Liu-Chen.

\section{References}

Al-Hasani R and Bruchas MR (2011) Molecular mechanisms of opioid receptordependent signaling and behavior. Anesthesiology 115:1363-1381.

Ansonoff MA, Zhang J, Czyzyk T, Rothman RB, Stewart J, Xu H, Zjwiony J, Siebert DJ, Yang F, Roth BL, et al. (2006) Antinociceptive and hypothermic effects of Salvinorin A are abolished in a novel strain of kappa-opioid receptor-1 knockout mice. J Pharmacol Exp Ther 318:641-648.

Appleyard SM, Celver J, Pineda V, Kovoor A, Wayman GA, and Chavkin C (1999) Agonist-dependent desensitization of the kappa opioid receptor by $\mathrm{G}$ protein receptor kinase and beta-arrestin. J Biol Chem 274:23802-23807.

Belcheva MM, Vogel Z, Ignatova E, Avidor-Reiss T, Zippel R, Levy R, Young EC, Barg J, and Coscia CJ (1998) Opioid modulation of extracellular signal-regulated protein kinase activity is ras-dependent and involves Gbetagamma subunits. J Neurochem 70:635-645.

Belcheva MM, Clark AL, Haas PD, Serna JS, Hahn JW, Kiss A, and Coscia CJ (2005) $\mathrm{Mu}$ and kappa opioid receptors activate ERK/MAPK via different protein kinase $\mathrm{C}$ isoforms and secondary messengers in astrocytes. J Biol Chem 280: 27662-27669.

Bian JS, Zhang WM, Pei JM, and Wong TM (2000) The role of phosphodiesterase in mediating the effect of protein kinase $\mathrm{C}$ on cyclic AMP accumulation upon kappaopioid receptor stimulation in the rat heart. J Pharmacol Exp Ther 292:1065-1070.

Bohn LM, Belcheva MM, and Coscia CJ (2000) Mitogenic signaling via endogenous kappa-opioid receptors in C6 glioma cells: evidence for the involvement of protein kinase $\mathrm{C}$ and the mitogen-activated protein kinase signaling cascade. $J$ Neurochem 74:564-573.

Bruchas MR, Macey TA, Lowe JD, and Chavkin C (2006) Kappa opioid receptor activation of p38 MAPK is GRK3- and arrestin-dependent in neurons and astrocytes. J Biol Chem 281:18081-18089.

Burns RN, Singh M, Senatorov IS, and Moniri NH (2014) Mechanisms of homologous and heterologous phosphorylation of FFA receptor 4 (GPR120): GRK6 and PKC mediate phosphorylation of $\mathrm{Thr}^{347}, \mathrm{Ser}^{350}$, and $\mathrm{Ser}^{357}$ in the C-terminal tail. Biochem Pharmacol 87:650-659.

Butcher AJ, Kong KC, Prihandoko R, and Tobin AB (2012) Physiological role of G-protein coupled receptor phosphorylation. Handb Exp Pharmacol 208:79-94.

Chen C, Chiu YT, Wu W, Huang P, Mann A, Schulz S, and Liu-Chen LY (2016) Determination of sites of U50,488H-promoted phosphorylation of the mouse kappa opioid receptor (KOPR): disconnect between KOPR phosphorylation and internalization. Biochem J 473(part 4):497-508.

Chen YJ, Oldfield S, Butcher AJ, Tobin AB, Saxena K, Gurevich VV, Benovic JL, Henderson G, and Kelly E (2013) Identification of phosphorylation sites in the $\mathrm{COOH}$-terminal tail of the $\mu$-opioid receptor. $J$ Neurochem 124:189-199.

Chuang TT, LeVine H, III, and De Blasi A (1995) Phosphorylation and activation of beta-adrenergic receptor kinase by protein kinase C. J Biol Chem 270: 18660-18665.

Cowan A, Kehner GB, and Inan S (2015) Targeting itch with ligands selective for $\mathrm{k}$ opioid receptors. Handb Exp Pharmacol 226:291-314.

Doll C, Pöll F, Peuker K, Loktev A, Glück L, and Schulz S (2012) Deciphering $\mu$-opioid receptor phosphorylation and dephosphorylation in HEK293 cells. $\mathrm{Br} J$ Pharmacol 167:1259-1270.

Herbert JM, Augereau JM, Gleye J, and Maffrand JP (1990) Chelerythrine is a potent and specific inhibitor of protein kinase C. Biochem Biophys Res Commun 172:993-999.

Hofmann J (1997) The potential for isoenzyme-selective modulation of protein kinase C. FASEB J 11:649-669.

Hull LC, Llorente J, Gabra BH, Smith FL, Kelly E, Bailey C, Henderson G, and Dewey WL (2010) The effect of protein kinase C and G protein-coupled receptor kinase inhibition on tolerance induced by mu-opioid agonists of different efficacy. J Pharmacol Exp Ther 332:1127-1135

Illing S, Mann A, and Schulz S (2014) Heterologous regulation of agonistindependent $\mu$-opioid receptor phosphorylation by protein kinase C. $\mathrm{Br}$ J Pharmacol 171:1330-1340.

Jacobson PB, Kuchera SL, Metz A, Schächtele C, Imre K, and Schrier DJ (1995) Antiinflammatory properties of Gö 6850: a selective inhibitor of protein kinase C. $J$ Pharmacol Exp Ther 275:995-1002.

Jamshidi RJ, Jacobs BA, Sullivan LC, Chavera TA, Saylor RM, Prisinzano TE, Clarke WP, and Berg KA (2015) Functional selectivity of kappa opioid receptor agonists in peripheral sensory neurons. J Pharmacol Exp Ther 355:174-182.

Johnson EA, Oldfield S, Braksator E, Gonzalez-Cuello A, Couch D, Hall KJ, Mundell SJ, Bailey CP, Kelly E, and Henderson G (2006) Agonist-selective mechanisms of mu-opioid receptor desensitization in human embryonic kidney 293 cells. Mol Pharmacol 70:676-685.

Law P-Y (2011) Opioid receptor signal transduction mechanisms, in The Opiate Receptors (Pasternak GW, ed) pp 195-238, Humana Press, New York, NY.

Lemos JC and Chavkin C (2011) Kappa opioid receptor function, in The Opiate Receptors (Pasternak GW, ed) pp 265-306, Humana Press, New York, NY.

Li J, Li JG, Chen C, Zhang F, and Liu-Chen LY (2002) Molecular basis of differences in (-) (trans)-3,4-dichloro-N-methyl-N-[2-(1-pyrrolidiny)-cyclohexyl]benzeneacetamide-induced desensitization and phosphorylation between human and rat kappa-opioid receptors expressed in Chinese hamster ovary cells. Mol Pharmacol 61:73-84. 
Li J-G, Luo LY, Krupnick JG, Benovic JL, and Liu-Chen L-Y (1999) U50,488H-induced internalization of the human kappa opioid receptor involves a beta-arrestin- and dynamin-dependent mechanism. Kappa receptor internalization is not required for mitogen-activated protein kinase activation. J Biol Chem 274:12087-12094.

Liu-Chen L-Y (2004) Agonist-induced regulation and trafficking of kappa opioid receptors. Life Sci 75:511-536.

Lowe JD, Sanderson HS, Cooke AE, Ostovar M, Tsisanova E, Withey SL, Chavkin C, Husbands SM, Kelly E, Henderson G, et al. (2015) Role of G protein-coupled receptor kinases 2 and 3 in $\mu$-opioid receptor desensitization and internalization. Mol Pharmacol 88:347-356. Mann A, Illing S, Miess E, and Schulz S (2015) Different mechanisms of homologous and heterologous $\mu$-opioid receptor phosphorylation. $\mathrm{Br} J$ Pharmacol 172:311-316.

Martiny-Baron G, Kazanietz MG, Mischak H, Blumberg PM, Kochs G, Hug H, Marmé D, and Schächtele C (1993) Selective inhibition of protein kinase C isozymes by the indolocarbazole Gö 6976. J Biol Chem 268:9194-9197.

McLaughlin JP, Xu M, Mackie K, and Chavkin C (2003) Phosphorylation of a carboxyl-terminal serine within the kappa-opioid receptor produces desensitization and internalization. $J$ Biol Chem 278:34631-34640.

McLennan GP, Kiss A, Miyatake M, Belcheva MM, Chambers KT, Pozek JJ, Mohabbat Y, Moyer RA, Bohn LM, and Coscia CJ (2008) Kappa opioids promote the proliferation of astrocytes via Gbetagamma and beta-arrestin 2-dependent MAPK-mediated pathways. J Neurochem 107:1753-1765.

Nobles KN, Xiao K, Ahn S, Shukla AK, Lam CM, Rajagopal S, Strachan RT, Huang TY, Bressler EA, Hara MR, et al. (2011) Distinct phosphorylation sites on the $\beta(2)$-adrenergic receptor establish a barcode that encodes differential function of $\beta$-arrestin. Sci Signal 4:ra51.
Pronin AN and Benovic JL (1997) Regulation of the G protein-coupled receptor kinase GRK5 by protein kinase C. J Biol Chem 272:3806-3812.

Schulz R, Wehmeyer A, and Schulz K (2002) Visualizing preference of G protein coupled receptor kinase 3 for the process of kappa-opioid receptor sequestration. Mol Pharmacol 61:1444-1452.

Simonin F, Valverde O, Smadja C, Slowe S, Kitchen I, Dierich A, Le Meur M, Roques BP, Maldonado R, and Kieffer BL (1998) Disruption of the kappa-opioid receptor gene in mice enhances sensitivity to chemical visceral pain, impairs pharmacological actions of the selective kappa-agonist U-50,488H and attenuates morphine withdrawal. EMBO $J$ 17:886-897.

Tobin AB (2008) G-protein-coupled receptor phosphorylation: where, when and by whom. Br J Pharmacol 153 (Suppl. 1):S167-S176.

Tobin AB, Butcher AJ, and Kong KC (2008) Location, location, location...site-specific GPCR phosphorylation offers a mechanism for cell-type-specific signalling. Trends Pharmacol Sci 29:413-420.

Winstel R, Freund S, Krasel C, Hoppe E, and Lohse MJ (1996) Protein kinase crosstalk: membrane targeting of the beta-adrenergic receptor kinase by protein kinase C. Proc Natl Acad Sci USA 93:2105-2109.

Address correspondence to: Dr. Lee-Yuan Liu-Chen, Center for Substance Abuse Research and Department of Pharmacology, Temple University Lewis Katz School of Medicine, 3500 North Broad Street, MERB 851, Philadelphia, PA 19140. E-mail: lliuche@temple.edu 